\title{
1 Does Vergence Affect Perceived Size?
}

2 Paul Linton

3

4 Centre for Applied Vision Research, City, University of London

5 Northampton Square, Clerkenwell, London EC1V 0HB

6 paul@linton.vision

8 Visual Scale - Size Constancy - Vergence - Taylor Illusion - Multisensory Integration

9

\section{Abstract}

Since Kepler (1604) and Descartes (1637), it's been suggested that 'vergence' (the angular rotation of the eyes) plays a key role in size constancy. However, this has never been tested divorced from confounding cues such as changes in the retinal image. In our experiment participants viewed a target which grew or shrank over 5 seconds. At the same time the fixation distance specified by vergence was reduced from $50 \mathrm{~cm}$ to $25 \mathrm{~cm}$. The question was whether the reduction in the viewing distance specified by vergence biased the participants' judgements of whether the target grew or shrank? We found no evidence of any bias, and therefore no evidence that eye movements affect perceived size. If this is correct, then this finding has three implications: First, perceived size is much more reliant on cognitive influences than previously thought. This is consistent with the argument that visual scale is purely cognitive in nature (Linton, 2017; 2018). Second, it leads us to question whether the vergence modulation of V1 contributes to size constancy. Third, given the interaction between vergence, proprioception, and the retinal image in the Taylor illusion, it leads us to ask whether this cognitive approach could also be applied to multisensory integration. 


\section{Introduction}

27 As objects move forwards or backwards in space, the image they cast on the retina varies drastically in size. And yet objects don't appear to change dramatically in size when they move closer or

29 further away. This suggests that there is a neural mechanism ('size constancy') that compensates

30 for the drastic changes in the retinal image caused by changes in distance (for a review see 31 Sperandio \& Chouinard, 2015). We can distinguish between two kinds of visual cues for size 32 constancy: 1. Pictorial Cues, which are present in the static monocular retinal image (such as 33 familiar size and perspective), and which account for the impression of size constancy in pictures.

34 And 2. Triangulation Cues, which typically rely on introducing multiple viewpoints either simultaneously (vergence and binocular disparities) or consecutively (motion parallax). cues since $2 \mathrm{D}$ pictures are more easily presented to participants in fMRI scanners (e.g. Murray et al., 2006). However, pictorial cues are neither necessary nor sufficient for size constancy. First, pictorial cues are unnecessary because, as we shall discuss below, observers in the Taylor illusion

40 appear to experience something close to full size constancy from vergence alone. Second, pictorial cues are insufficient because, as Sperandio et al. (2012) observe, size constancy in pictures is merely

42 a fraction (10\%-45\%) of the size constancy experienced in the real world (Murray et al., 2006;

43 Leibowitz et al., 1969; Goodale, 2020 estimates 10\%-30\%; see also Millard et al., 2020 for a recent

44 attempt to disambiguate static monocular and binocular size constancy, although recognising vergence may have influenced their monocular results). To spell out this claim, consider the kind of stimulus used in Murray et al. (2006): 
bioRxiv preprint doi: https:/doi.org/10.1101/2020.02 23.961649; this version posted June 20, 2021. The copyright holder for this preprint (which was not certified by peer review) is the author/funder, who has granted bioRxiv a license to display the preprint in perpetuity. It is made available under aCC-BY 4.0 International license.

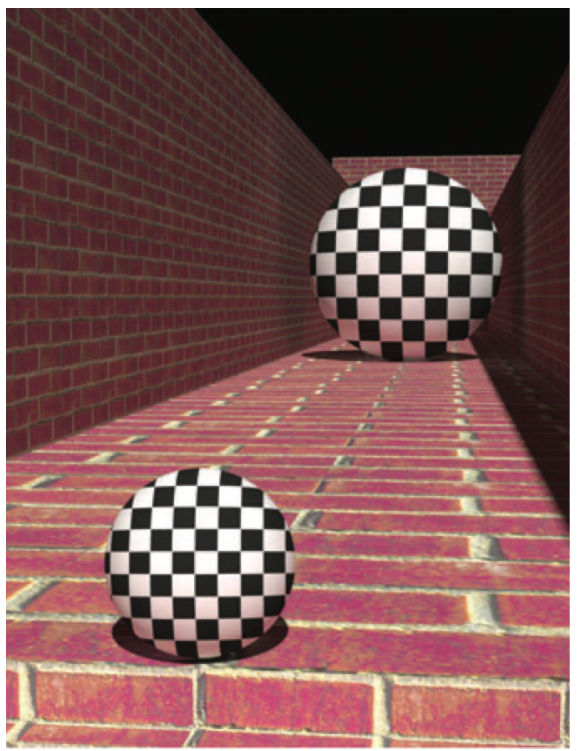

Figure 1. Demonstration of pictorial size constancy in the stimulus used by Murray et al. (2006)

(C) Scott Murray)

We judge the further ball in Fig.1 to be many times larger in physical size than the nearer ball. But we also judge the further ball to take up more of the picture than the nearer ball even though they have the same angular size in the picture. This apparent increase in angular size is the phenomenon that size constancy is concerned with. In Murray et al. (2006) the further ball was judged to $17 \%$ larger in angular size than the nearer ball.

When reviewing the literature, we have to keep the distinction between perceived physical size and perceived angular size in mind. For instance, Sperandio et al. (2012) contrast the partial $(10 \%-45 \%)$ size constancy in pictures with the full (100\%) size constancy experienced in the real world according to Emmert's Law (Emmert, 1881). However, Emmert's Law is a claim about perceived physical size not perceived angular size. Indeed, the essence of Emmert's Law is the claim that perceived physical size varies proportionately with perceived physical distance when the perceived angular size is fixed. By contrast, an angular size interpretation of Emmert's Law would falsely imply that objects do not reduce in perceived angular size with distance. 
Nonetheless, even with the distinction between physical size and angular size in mind,

66

67

68

69

vergence is thought to play an important contribution to the perceived angular size of objects, known as vergence size constancy.

2. Triangulation Cues: In terms of triangulation cues to size constancy (vergence, accommodation, binocular disparity, motion parallax, defocus blur), the emphasis has been on vergence. First, motion parallax is neither necessary for size constancy (full size constancy is observed by participants in an fMRI scanner in Sperandio et al., 2012), nor is there particularly strong evidence that motion parallax contributes to size constancy (Combe \& Wexler, 2010 only marginally qualify "the common notion that size constancy emerges as a result of retinal and vergence processing alone"). Second, binocular disparity is typically regarded as merely providing relative depth, and not absolute size and distance. Still, considering size constancy only requires relative changes in distance to be matched by relative changes in apparent size (distance ${ }_{1} \div$ distance $_{2}=$ size $_{1} \div$ size $_{2}$ ), a merely relative depth cue could suffice. The problem is that binocular disparity doesn't even provide relative depth information until it has been scaled by absolute distance information, which is typically assumed to come from vergence. As Brenner \& van Damme (1998) observe, a $1^{\circ}$ change in retinal disparity could equally reflect a change in distance of $20 \mathrm{~cm}$ to $21 \mathrm{~cm}(5 \%$ increase in distance) or $2 \mathrm{~m}$ to $4 \mathrm{~m}$ ( $100 \%$ increase in distance).

There is also a deeper conceptual point. Although Linton $(2017 ; 2018)$ explores the possibility that vision may be divorced from absolute size and distance, orthodox discussions of size constancy typically articulate it in terms of the visual system using absolute distance to determine perceived size. For instance, Emmert's Law (Emmert, 1881) is typically articulated as S $=\mathrm{c}(\mathrm{R} \times \mathrm{D})$, where $\mathrm{S}$ is perceived size, $\mathrm{c}$ is a constant, $\mathrm{R}$ is retinal image size, and $\mathrm{D}$ is perceived distance. But, as we already mentioned, binocular disparity is typically thought of as being a merely relative depth cue outside very limited circumstances (objects taking up at least $20^{\circ}$ of the visual field; Rogers \& Bradshaw, 1995). Instead, vergence is typically cited as being one of our most 
important absolute distance cues at near distances (Mon-Williams \& Tresilian, 1999; Viguier et al., 2001; for a review and challenge to this consensus, see Linton, 2020).

Kepler (1604) and Descartes (1637) were the first to suggest that the visual system uses vergence (the angular rotation of the eyes) to scale the size of the retinal image. Evidence for vergence size constancy has come from four specific contexts where it has been found that changing the vergence angle affects the perceived size of objects (so-called 'vergence micropsia'):

1. Wallpaper Illusion: Before the invention of the stereoscope by Wheatstone (1838), the earliest evidence of vergence micropsia was the 'wallpaper illusion', the observation that if you cross your eyes whilst looking at a recurring wallpaper pattern, the wallpaper pattern appears smaller and closer (Smith, 1738; Priestley, 1772; Goethe, 1810; Meyer, 1842, 1852; Brewster, 1844; Locke, 1849; Lie, 1965; Ono et al., 1971; Kohly \& Ono, 2002; see Howard, 2012 for review).

2. Stereoscopic Viewing: The invention of the stereoscope by Wheatstone (1838) (which presents separate images to each eye) enabled the eyes to be rotated independently of the retinal image. Wheatstone observed that if eye rotation was increased, the perceived image appeared to shrink, even though the images shown to each eye remained fixed (Wheatstone, 1852; Helmholtz, 1866, p.313; Judd, 1897; Frank, 1930; Hermans, 1937, 1954; Locke, 1938; Adams, 1955; Von Holst, 1955a, 1955b, 1957; Heinemann et al., 1959; Gogel, 1962; Biersdorf et al., 1963; Wallach \& Zuckerman, 1963; McCready, 1965; Leibowitz \& Moore, 1966; Leibowitz et al., 1972; Komoda \& Ono, 1974; Regan et al., 1986; Enright, 1989).

3. Telestereoscopic Viewing: Building on Wheatstone (1838), Helmholtz (1857) invented the telestereoscope, and observed that if we use mirrors to artificially increase the distance between the two eyes, the world appears miniaturised. In his Treatise on Physiological Optics he observed that "it will seem as if the observer were not looking at the natural landscape itself, but a very exquisite and exact model of it, reduced in scale" (Helmholtz, 1866, p.312). This effect has been attributed to vergence by Helmholtz (1857; 1858; 1866, p.310) and Rogers (2009; 2011), since the eyes need to rotate more to fixate on the same physical distance (cf. Linton, 2018 for an alternative account 
116 discussed below), and has been extensively studied in the military research (where helicopter pilots

117 often view the world through cameras with increased interpupillary separation, see Newman \&

118 Ostler, 2009; Stuart et al., 2009; and Priot et al., 2010; 2011; 2012; 2018).

119 4. Taylor Illusion: Vergence is also thought to be central to the multisensory integration of

120 hand motion and the retinal image in the Taylor illusion. If you make an after-image of your hand

121 with a bright flash, and then in complete darkness move your hand closer to your face, the after-

122 image of your hand appears to shrink even though it is fixed on the retina (Taylor, 1941). The best

123 current explanation for the Taylor illusion is that it is due (Taylor, 1941; Morrison \& Whiteside,

124 1984; Mon-Williams et al., 1997) or almost entirely due (Sperandio et al., 2013) to the increase in

125 vergence as the eyes track the physical hand in darkness (see also Gregory et al., 1959; Carey \&

126 Allan, 1996; Bross, 2000; Ramsay et al., 2007; Faivre et al., 2017a; and for vergence scaling of after-

127 images see Urist, 1959; Suzuki, 1986; Lou, 2007; Zenkin \& Petrov, 2015). Importantly, when

128 Sperandio et al. (2013) moved the participant's hand and vergence in opposite directions, they

129 found that (a) the after-image size changed in the direction of vergence, not the hand movement,

130 and (b) the magnitude of the size change when vergence and the hand were in conflict was almost

131 as large as when both the hand and vergence were moving in the same direction.

132 Surveying the literature on vergence micropsia, two things are striking: First, to our

133 knowledge, there has never been a report of a failure of vergence micropsia within peripersonal

134 space (near distances corresponding to arms reach). Even on the rare occasions when a change in

135 vergence fails to provide an impression of motion-in-depth (for instance, when motion-in-depth

136 is vetoed by a stimulus that takes up the whole visual field) as in Regan et al. (1986), the authors

137 still report "apparent size changes as about threefold when convergence changed from about 0

138 deg to 25 deg", with the authors observing: "Changes in size and depth produced by ocular

139 vergence changes are well known".

140 Second, the after-image literature appears to suggest that vergence provides something

141 close to perfect size constancy for distances between $25-50 \mathrm{~cm}$. This can be seen for two reasons: 
142 First, because size constancy appears close to perfect for $25-50 \mathrm{~cm}$ when vergence is the only

143 distance cue. Apparent size doubled for the representative subject in Sperandio et al. (2013)

144 (incongruent condition) from $3.3 \mathrm{~cm}$ at $25 \mathrm{~cm}$ (suggested by the $y=-0.61 x+3.3$ line of best fit) to

$1456.3 \mathrm{~cm}$ at $50 \mathrm{~cm}$ (average of size estimates after a $>3^{\circ}$ vergence eye movement) (my analysis of their

146 Fig.5 using WebPlotDigitizer 4.2; Marin et al., 2017). Second, the same conclusion is arrived at by

147 a combination of the fact that (a) the Taylor illusion provides near perfect size constancy in this

148 distance range (Bross, 2000; Ramsay et al., 2007; Sperandio et al., 2013), coupled with the fact that

149 (b) the Taylor illusion can be attributed almost entirely to vergence (Sperandio et al., 2013).

$150 \quad$ Vergence size constancy is therefore regarded as a fundamental aspect of visual perception.

151 However, we believe that vergence size constancy should be re-evaluated for two reasons:

152 First, our recent work suggests that vergence is an ineffective absolute distance cue once

153 confounding cues have been controlled for. Participants are unable to use vergence to judge

154 absolute distance (Linton, 2020), and we are reluctant to embrace the possibility (raised by Ono \&

155 Comerford, 1977 and Bishop, 1989) that vergence might still be an effective size constancy cue

156 even if it proves to be ineffective for absolute distance judgements.

157 Second, one surprising fact is that to the best of our knowledge vergence size constancy

158 has never been tested divorced from confounding cues (changes in the retinal image, such as

159 diplopia or retinal slip, or changes in hand position) which inform the observer about changes in

160 distance. The reason for this is easy to appreciate. Vergence can only be driven in one of two ways.

161 Either participants track the retinal slip of a visual object moving in depth (such as an LED: Mon-

162 Williams et al., 1997; Sperandio et al., 2013), in which case participants are informed about the

163 change in distance by binocular disparity (the apparent retinal slip of the stimulus as it moves in

164 depth). Or participants track their own hand moving in depth (as in the Taylor illusion), but this

165 gives them proprioceptive information about the changing distance instead. The purpose of our

166 experiment was therefore to test vergence size constancy in a context where it is known to be 
bioRxiv preprint doi: https:/doi.org/10.1101/2020.02 23.961649; this version posted June 20, 2021. The copyright holder for this preprint (which was not certified by peer review) is the author/funder, who has granted bioRxiv a license to display the preprint in perpetuity. It is made available under aCC-BY 4.0 International license.

effective (vergence changes over 5 seconds from $25 \mathrm{~cm}$ to $50 \mathrm{~cm}$ : Sperandio et al., 2013), but in a way that controls for subjective knowledge about the changing distance.

\section{Materials and Methods}

171 Participants viewed two targets on a display fixed $160 \mathrm{~cm}$ away through two metal occluders that ensured that the left eye only saw the right target and the right eye only saw the left target. We were therefore able to manipulate the vergence distance specified by the targets (indicated by the arrow in Fig.2) by changing the separation between the targets on the fixed display.
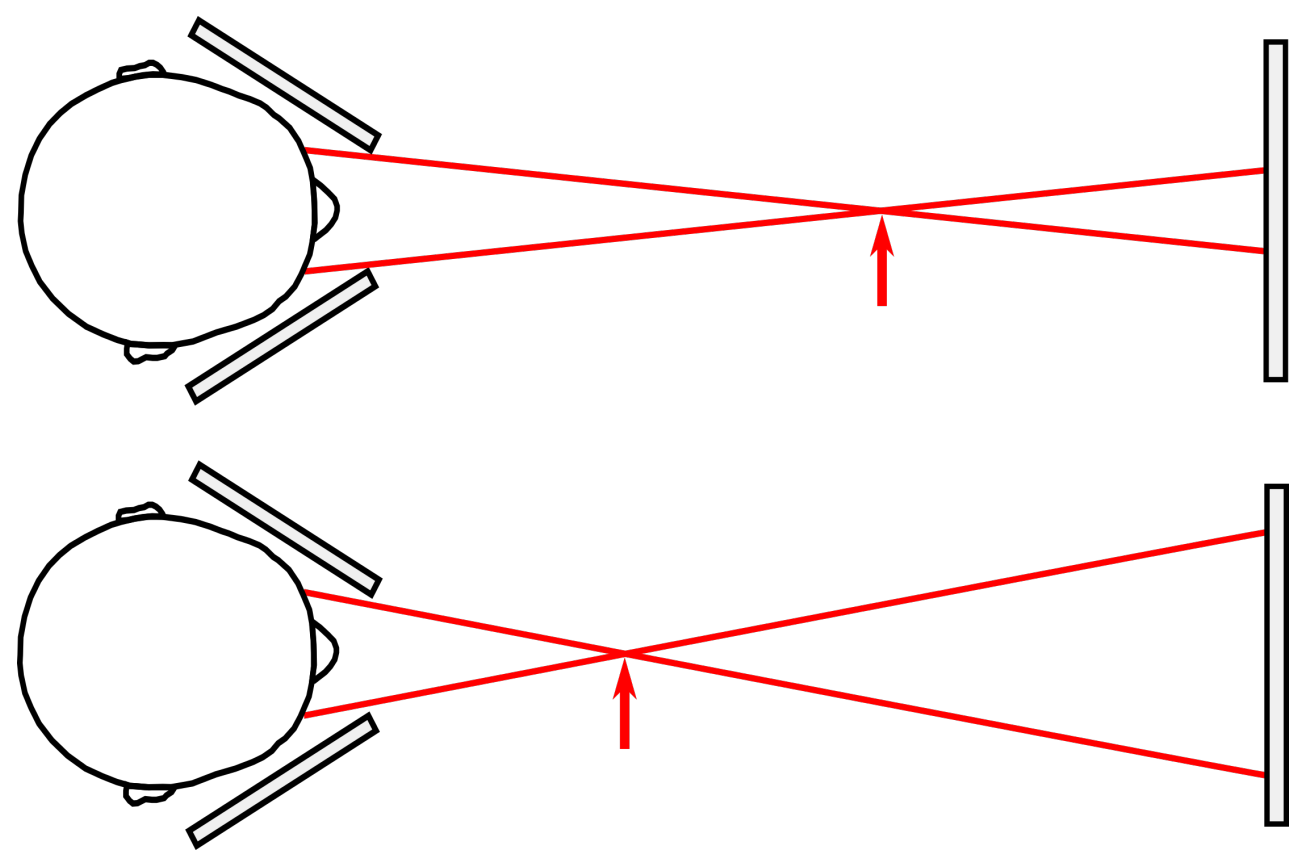

177 Figure 2. Illustration of how the vergence specified distance was manipulated in the experiment using a fixed display. By increasing the separation between the targets on the display (compare top and bottom images) we were able to reduce the vergence specified distance.

181 Before the experiment began, participants rotated the metal plates to ensure that they only saw one target in each eye, and were asked to report if the targets ever went double. Our apparatus 
the stimulus), coupled with (b) a subjective criterion (diplopia; whether the target went double) to

187 because they couldn't fuse the target, and 2 because they experienced the target as blurry.

First, we built an objective estimate of size change into the target itself. The vergence size constancy literature typically relies upon viewing an after-image (which has a fixed retinal size) and then asking participants to subjectively evaluate the change in perceived size after a vergence

193 change by (1) asking participants to match their visual experience to (a) a visible chart (Bross, 2000;

194 Lou, 2007; Sperandio et al., 2013) or (b) a memorised chart (Ramsay et al., 2007), or (2) by asking participants to make a conscious size judgement of (a) the physical size of the after-image (Monquantify this by increasing the physical size of the target during the vergence change and estimating at what increase in physical size participants are at chance in determining whether the target got

201 larger or smaller. The target (illustrated in Fig.3) consisted of two horizontals bars connected by a

202 vertical bar. It was $3^{\circ}$ in angular size (width and height) at the start of the trial. On each trial the vergence specified distance of the target reduced from $50 \mathrm{~cm}$ to $25 \mathrm{~cm}$ over 5 seconds. At the same time, the physical size of the target on the display increased or decreased by between $-20 \%$ and $+20 \%$, and participants had to make a forced choice using a button press whether the target got bigger or smaller (“did the target get bigger or smaller?”). 


\section{Subjects view target over 5 seconds that}

\section{Increases in physical separation on the display, reducing the vergence specified distance from $50 \mathrm{~cm}$ to $25 \mathrm{~cm}$}

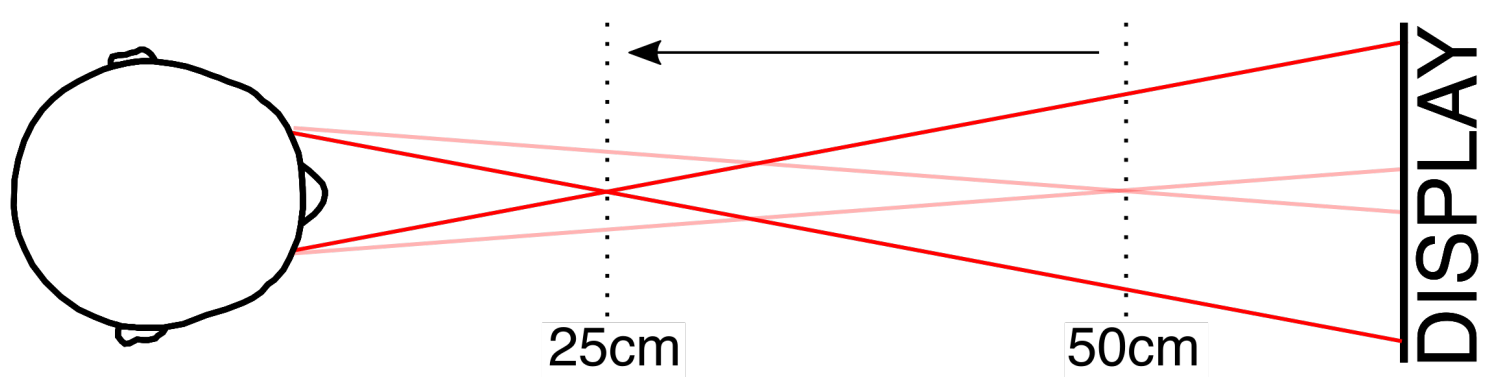

\section{At the same time the physical size of the target on the display increases or reduces}

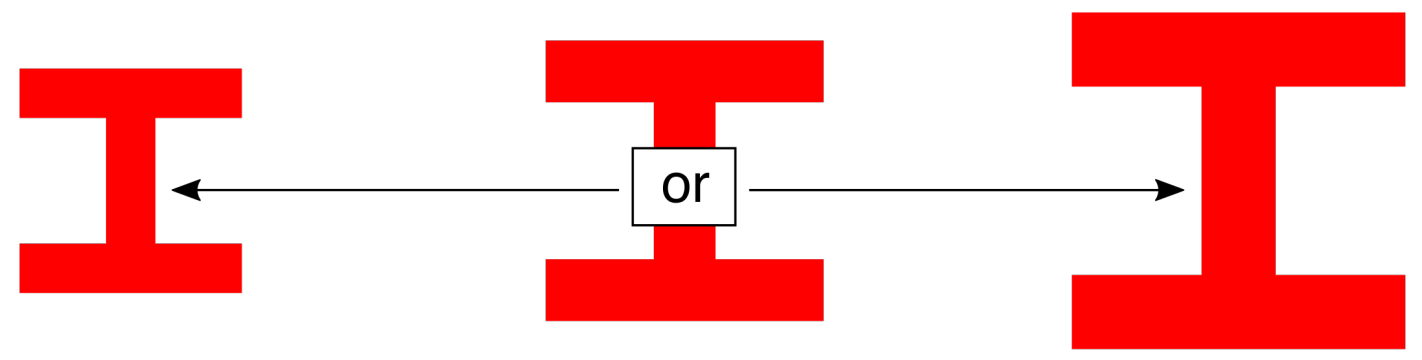

\section{And participants are asked "Did the target get bigger or smaller?"}

213 Figure 3. Summary of the two simultaneous manipulations of the targets during each trial of (a)

214 the physical separation of the targets on the display, that manipulated the vergence specified distance of the target, and (b) the physical size of the targets on the display. Participants were asked to judge whether the target got bigger or smaller? 
bioRxiv preprint doi: https:/doi.org/10.1101/2020.02 23 961649: this version posted June 20, 2021. The copyright holder for this preprint (which was not certified by peer review) is the author/funder, who has granted bioRxiv a license to display the preprint in perpetuity. It is made available under aCC-BY 4.0 International license.

221

222

223

224

225

226

227

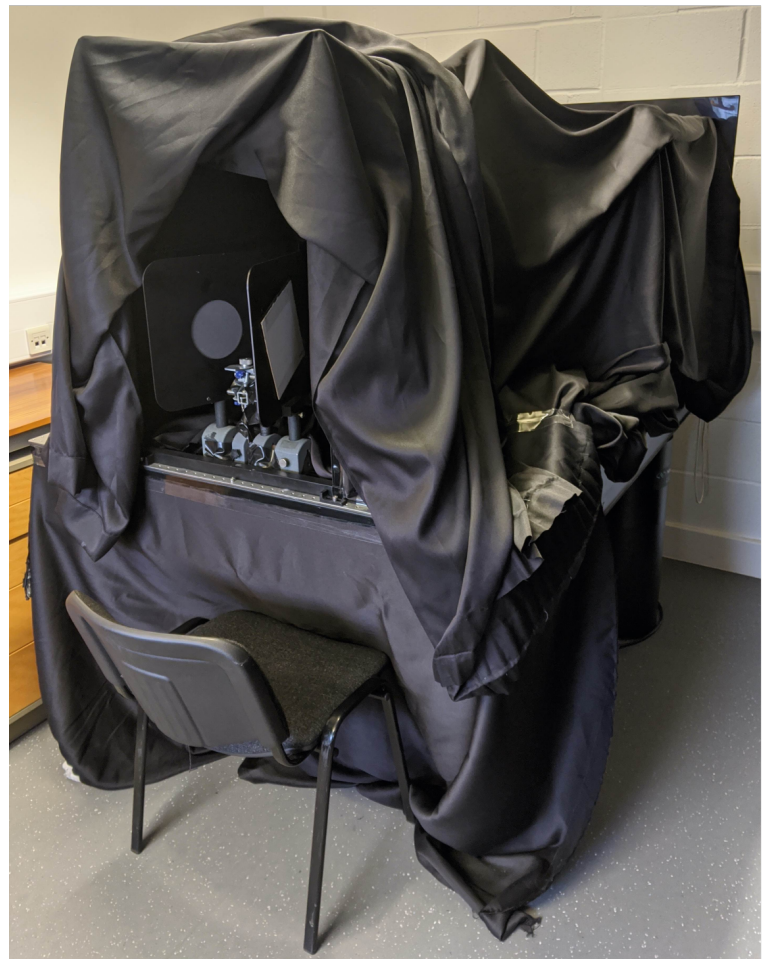

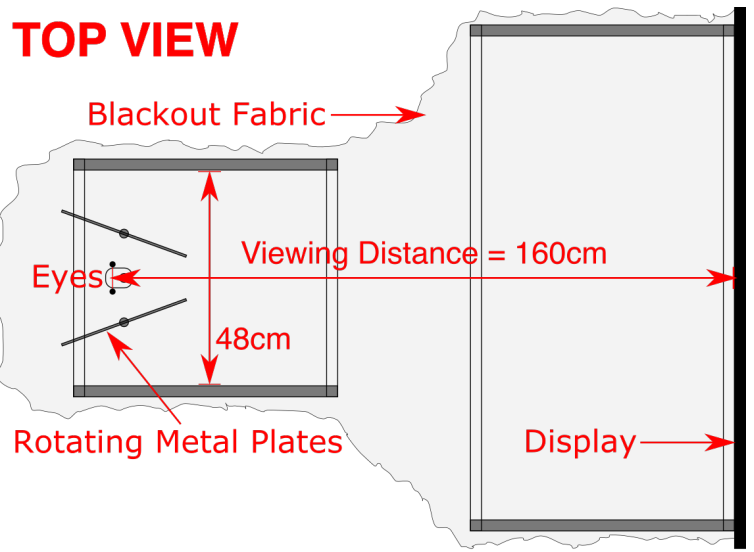

\section{SIDE VIEW}

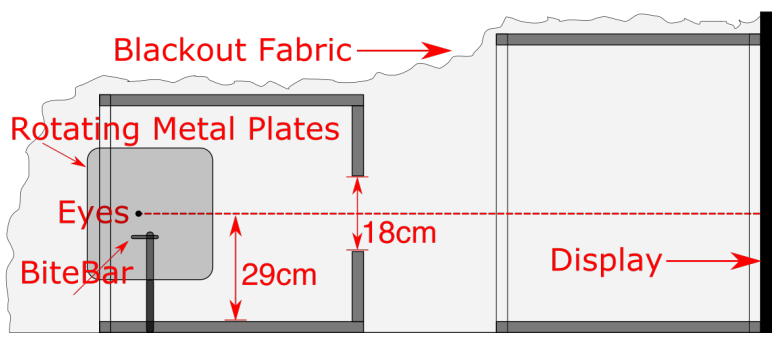

232 Figure 4. Photograph and cross-section plans of the apparatus. 
but subjectively invisible to the participant themselves. This we achieved with a $3^{\circ}$ target moving in depth from $50 \mathrm{~cm}$ to $25 \mathrm{~cm}$ over 5 seconds. Although this motion in depth is gradual (equivalent to an average speed of $5 \mathrm{~cm} /$ second, corresponding to an average vergence angle change of $1.4^{\circ} / \mathrm{s}$ ), this is consistent with the changes in vergence in Sperandio et al. (2013) $(25 \mathrm{~cm}$ to $50 \mathrm{~cm}$ over 5

241 seconds), where close to perfect vergence size constancy was previously reported. We expected

242 that using a target rather than an LED would have this effect for two reasons. First, being slightly

243 larger on the retina, it was likely to improve vergence tracking of the target. Second, any remaining

244 retinal slip would be less discriminable against a slightly larger target. targets to maintain a constant radius from, and orientation to, the eye. This was achieved in

\section{A. Ideal to Approximate}

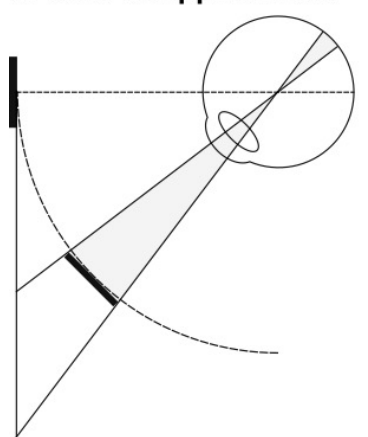

B. Projection onto Display

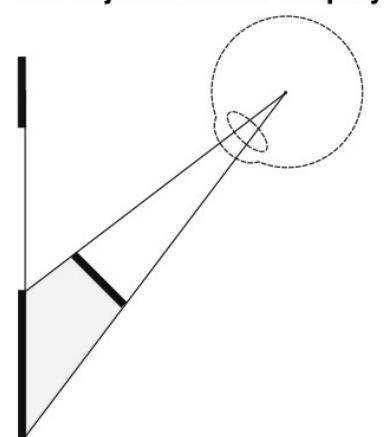

C. Correct Retinal Image

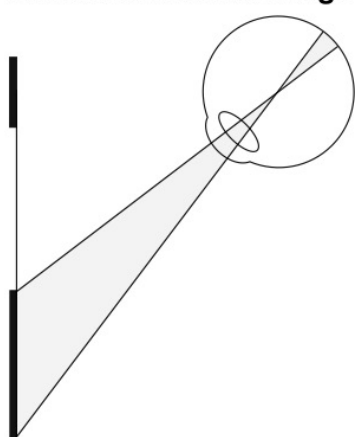

Figure 5. OpenGL rendering of target achieves the correct retinal image for a target with a constant radius and orientation to the eye, whilst presenting the target on a fronto-parallel display. 
5. Fifth, another challenge of this display is that it requires the eyes to focus (or 'accommodate') at the distance of the display $(160 \mathrm{~cm})$, whilst vergence (the angular rotation of the eyes) is at $25-50 \mathrm{~cm}$. This decoupling of vergence and accommodation doesn't happen in normal viewing conditions, and too much vergence-accommodation conflict can lead to the target going blurry or double (Hoffman et al., 2008). To solve this problem we had an optometrist fit each participant with contact lenses (based on the participant's valid UK prescription) so that the optical distance of the display was $33 \mathrm{~cm}$ even though its physical distance was $160 \mathrm{~cm}$. This ensured a maximum of $+/-1$ dioptres of vergence-accommodation conflict, well within the zone of 'clear single binocular vision' (Hoffman et al., 2008). Indeed, some of the most dramatic reports of vergence micropsia have been in the presence of large vergence-accommodation conflicts (e.g. 6.5 dioptres in Regan et al., 1986), so the presence of $+/-1$ dioptre should not be objectionable. piloting, we found that the author (an experienced psychophysical observer) could not detect size changes over 5 seconds that were smaller than $1.5 \%$. So, if vergence changes the perceived size of the target by less than $1.5 \%$, vergence size constancy can be dismissed as smaller than the smallest effect size of interest under an inferiority test (Lakens et al., 2018; in our actual experiment this was revised down to $1.43 \%$, the detection threshold of our most sensitive observer). 


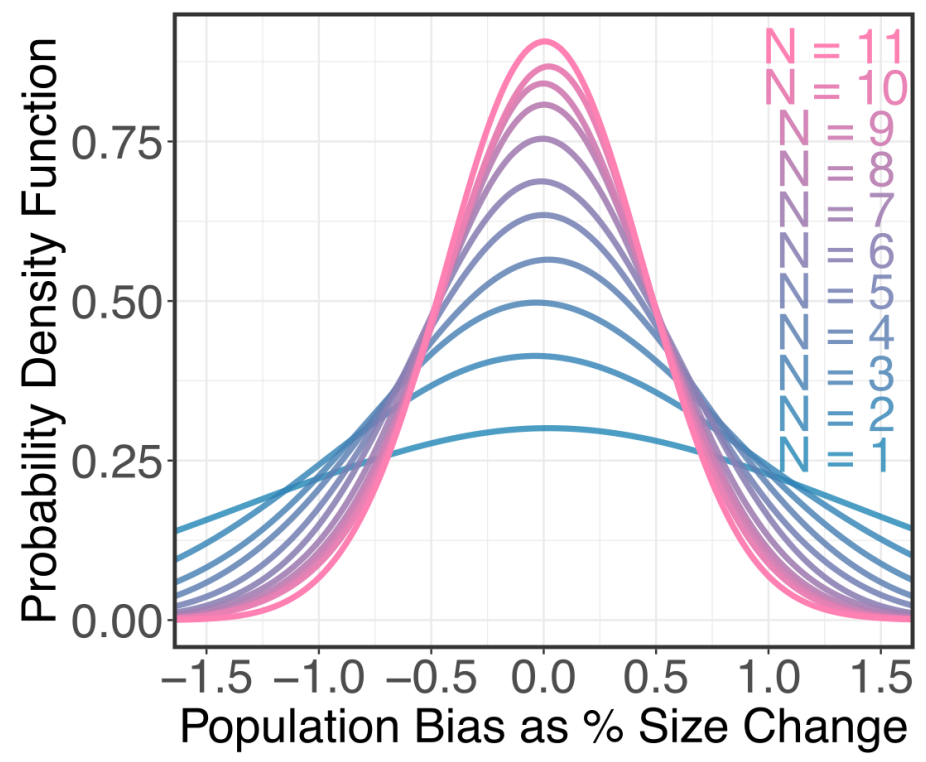

284 Figure 6. Simulated Experiment. We simulated the experiment 10,000 times in Quest+ (bias $=0$, 285 detection threshold $=5 \%$, lapse rate $=2 \%$ ) to model how increasing the number of participants 286 would improve the accuracy of our hierarchical Bayesian estimate of the true bias (true bias $=0$ ).

287 We determined that we needed $\mathrm{n} \geq 5$ to rule out an effect greater than our smallest effect size of 288 interest (vergence size constancy $>1.5 \%$ ).

11 observers (8 female, 3 male; age ranges 20-34, average age 24.5) participated in the experiment: the author and 10 participants recruited using an online advertisement (13 were originally recruited, but 1 was excluded because they could not fuse the target, and 2 were excluded because their vision was blurry with the contact lenses). All participants were screened to ensure their accommodation was within normal bounds for their age (tested with a RAF near-point rule), vergence within normal bounds (18D or above on a Clement Clarke prism bar), and stereoacuity within normal bounds (60 arc secs or less on a TNO stereo test). The author's participation was required to (a) confirm Quest+ mirrored the pilot data, and (b) provide a criterion for the 298 minimum effect size. All other subjects were naïve as to the purpose of the experiment, and were 299 paid $£_{15} / \mathrm{hr}$ for 3 hours. The study was approved by the School of Health Sciences Research 300 Ethics Committee at City, University of London in accordance with the Declaration of Helsinki. 


\section{Results}

306 Let us consider what we would expect to find according to (a) the null hypothesis (vergence has

307 no effect on perceived size) and (b) the alternative hypothesis (vergence has an effect on perceived

308 size). As we have already discussed, if vergence has no effect on perceived size, then participants

309 should be at chance at determining whether the target got bigger or smaller when we don't

310 introduce a size change (bias $=0$ ). By contrast, if participants experience something close to full

311 size constancy, then we would have to increase the size of the target by $100 \%$ in order to cancel

312 out the reduction in perceived size caused by vergence micropsia (which would equate to a $50 \%$

313 reduction in size, because halving the distance leads to a doubling of the retinal image size,

314 assuming the small angle approximation).

315 These two hypotheses, and various intermediate degrees of size constancy between these

316 two extremes, are plotted in Fig.4A. What the hierarchical Bayesian model of our results in Fig.4A

317 show is that the bias we found was $\approx 0$, consistent with there being no vergence size constancy. 


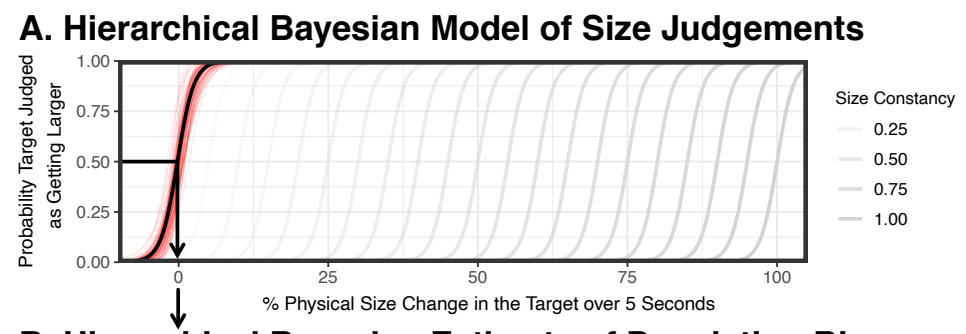

\section{B. Hierarchical Bayesian Estimate of Population Bias}
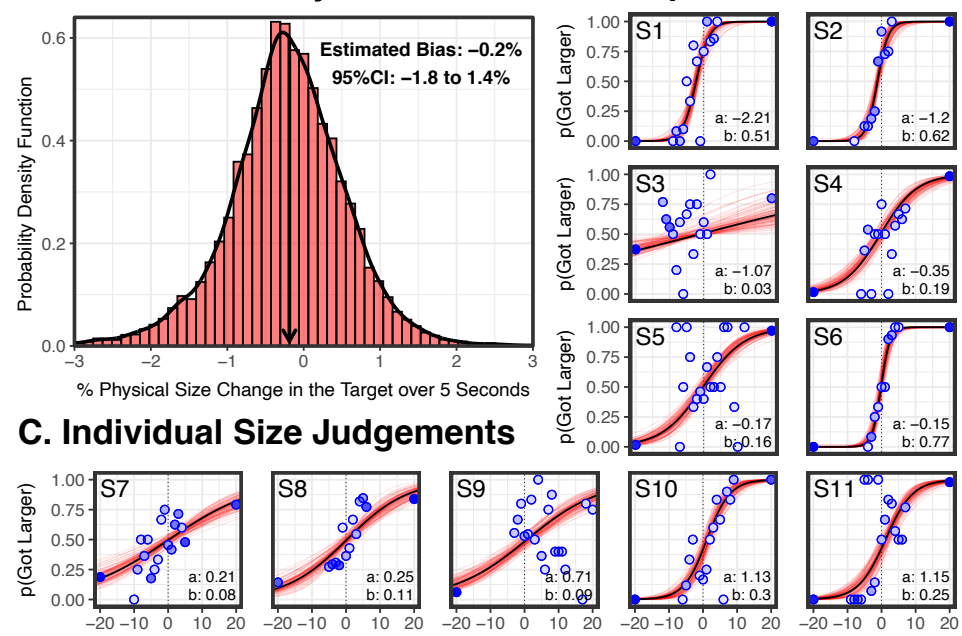

$\%$ Physical Size Change in the Target over 5 Seconds

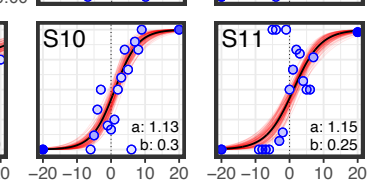

319 Figure 7. Results. A. Hierarchical Bayesian model of the population psychometric function in black

320 (based on 15,000 posterior estimates, 100 representative posterior estimates in red). Also shown

321 are predictions for various degrees of vergence size constancy effect sizes (in grey). B. Probability

322 density function of 15,000 posterior estimates of the population bias, with a non-significant bias

323 of $-0.2 \%$. C. Individual subject results fitted with Bayesian psychometric functions in black (based

on 15,000 posterior estimates, 100 representative posterior estimates in red). Blue dots indicating

the physical size changes tested by Quest+ (with darkness of the dot indicating the number of

participant, alpha (a) is the bias of the logistic function, and beta (b) is the slope.

To explain our conclusion, the individual results are plotted in Fig.7C. Each blue dot represents a

330 physical size change that was tested by the Quest+ maximum likelihood model, and the darkness

331 of the dot indicates the number of times it was tested. It's important to keep in mind that with

332 Quest+ no one data point should be viewed in isolation. The underlying assumption is that Quest+ 
333 is fitting a psychometric function to the data. On each trial Quest + tests the physical size change

334 that would be most informative to the four parameters of the psychometric function being

335 estimated (the slope, the bias, floor, and ceiling). If Quest+ tests one physical size change a few

336 times and finds performance at 100\%, and an almost identical size change and finds performance

337 at 0 , the interpretation is that the actual response is somewhere between these two extremes. Put

338 simply, from a Bayesian modelling perspective, there's nothing to suggest that these changes

339 between neighbouring data points reflects a wild variation in participant response.

340 We fit each of the individual sets of data with a four-parameter logistic Bayesian

341 psychometric function which estimates the slope, the bias, the floor, and the ceiling of the

342 psychometric function (indicated with a black line), using the Palamedes Toolbox 1.10.1 (Prins \&

343 Kingdom, 2018) with CmdStan 2.22.0, using the toolbox's standard priors (bias and slope: normal

$344(0,100)$, upper and lower lapse rates: beta $(1,10))$, and based on 15,000 posterior estimates $(100$

345 posterior estimates illustrated in red). Fig. $7 \mathrm{C}$ shows individual biases range from $-2.2 \%$ to $+1.2 \%$,

346 but cluster around 0 , as we would expect if vergence is having no effect on participants' size

347 judgements. Put simply, participants are perceiving the larger stimuli as larger and the smaller

348 stimuli as smaller, despite the changes in vergence.

349 To estimate the population level psychometric function illustrated in Fig.4A, we used the

350 Palamedes Toolbox 1.10.1 (Prins \& Kingdom, 2018) with CmdStan 2.22.0 to fit a four-parameter

351 logistic hierarchical Bayesian psychometric function, which fits the data with a multilevel model

352 that takes into account the variability of each subject. We used the toolbox's standard multilevel

353 priors which are documented by Prins \& Kingdom (2019) and, based on 15,000 posterior estimates

354 (100 posterior estimates illustrated in red), found a population level bias of $-0.219 \%$ ( $95 \%$ CI: -

$3551.82 \%$ to $1.39 \%$ ) and a population level slope of -0.732 ( $95 \%$ CI: -1.07 to 0.378 ).

356 The estimate that particularly interests us is the population bias, so in Fig.4B we provide a

357 probability density function of the 15,000 posterior estimates of the bias. We find no statistically 
significant bias, and therefore no statistically significant effect of vergence on perceived size.

Indeed, the non-significant bias of $-0.2 \%$ is in the wrong direction for size constancy.

361 hypothesis not rejected) to the positive claim that there is no effect of vergence on perceived size

362 (null hypothesis accepted), we can make two further arguments.

First, from a Bayesian perspective, we can perform a JZS Bayes factor (Rouder et al., 2009).

364 The estimated Bayes factor that we found was $3.99( \pm 0.03 \%)$, which suggests that the data are

365 four times more likely under the null hypothesis $($ bias $=0)$ than under the alternative $($ bias $\neq 0)$.

Second, from a frequentist perspective, we can perform an inferiority test that tests

367 whether, if there is a vergence size constancy effect, it is at least as large as the smallest effect size

of interest (Lakens et al., 2018). You'll remember, we defined our smallest effect size of interest as

the detection threshold for our most sensitive observer (which is $1.43 \%$ ). Put simply, any vergence

We therefore performed an inferiority test by taking the $90 \%$ confidence interval of the population

374 bias in Fig.4B in the predicted direction, which is $0.96 \%$. Since this is smaller than $1.43 \%$ (our

375 smallest effect size of interest), from a frequentist perspective we can conclude that any vergence

376 size constancy effect is effectively equivalent to zero (Lakens et al., 2018).

\section{Discussion}

380 According to the literature, "it is well known that vergence is a reliable source of depth information

381 for size constancy" (Sperandio et al., 2013). But we find no evidence that vergence makes any

382 contribution to perceived size. To our knowledge, ours is the first study to report a failure of

383 vergence size constancy at near distances. But ours is also the first study that controls for 
confounding perceptual cues (changes in the retinal image) whilst also controlling for confounding cognitive cues (keeping subjects naïve about changes in absolute distance).

3876 of the Discussion we explore these alternative explanations. Whilst we cannot definitively rule out these alternative explanations, we will go on to explain why we do not believe that they give the most plausible interpretation of our results.

1. Eye Tracking

393 We specifically chose not to employ eye tracking in our experiment for four reasons: First, Hooge et al. (2019) find that readily available research eye-trackers "are not accurate enough to be used impossible. Third, give the participants were fitted with contact lenses to set their accommodation at $33 \mathrm{~cm}$, but the display was at $160 \mathrm{~cm}$, ordinary techniques for eye tracking calibration (having

400 participants converge on points on the display $160 \mathrm{~cm}$ away) could not be employed. Fourth, given

401 our thesis that the vergence size constancy literature reflects cognitive influences rather than truly

402 perceptual effects, we were understandably reluctant to introduce any procedures that would inform participants about the mechanisms underpinning the apparatus, or that eye movements were important for the task being performed. participants were not converging during the experiment. Whilst this possibility can't be excluded,

407 we did employ a subjective criterion for binocular fusion, namely whether the participant reported 408 the target going double. Siegel \& Duncan (1960) find that for a $3^{\circ}$ target (which ours was, on average) the average maximum disparity participants fail to detect is $2.5^{\circ}$ or less. So our subjective 
410 criterion of binocular fusion should provide comparable accuracy to eye tracking where the 2D

411 gaze literature (Choe et al., 2016; Drewes et al., 2014; Wildenmann \& Schaeffel, 2013; Wyatt, 2010),

412 and the 3D gaze literature (Hooge et al., 2019) report errors of a similar magnitude (up to $\approx 2.5^{\circ}$ ).

413 Admittedly, there have been attempts to improve eye tracking accuracy. First, since eye

414 tracking errors are caused by changes in luminance affecting pupil size, one approach is to keep

415 luminance fixed. But it's not clear that controlling luminance is the right approach for our

416 experiment. If we controlled for luminance in our experiment, as the target got larger it would

417 have to get darker, and as the target got smaller it would have to get brighter. Second, Drewes et

418 al. (2014) found that even if luminance is not controlled, the error can be reduced (down from

$4192.5^{\circ}$ to $\left.0.5^{\circ}\right)$ by calibrating the eye tracker at different luminances. However, this still fails to control

420 for non-luminance effects on pupil size, including changes in pupil size with vergence (the 'near

421 triad': Balaban et al., 2018), and cognitive processes (Naber \& Nakayama, 2013), although these

422 are liable to be smaller than the errors induced by changes in luminance.

423 Another concern with our experiment is that participants might have been doing the task

424 with one eye closed, although they were told to keep both eyes open. But both this suggestion,

425 and the suggestion that participants failed to effectively converge, have to be understood in the

426 context of our two other experiments (reported in Linton, 2020) where a similar paradigm was

427 used to demonstrate that vergence was ineffective as an absolute distance cue. For these concerns

428 to be really driving our results in this paper and Linton (2020) we would have to conclude that 35

429 participants over 3 experiments collectively failed to report pervasive diplopia, or all conducted

430 the experiment with one eye closed, and there is no reason to believe that this is the case.

434 Another concern is that vergence and accommodation were decoupled, and this might have 435 affected the vergence response and/or placed the distance estimates from vergence and 
accommodation in conflict. However, as we have already discussed, some of the most impressive reports of vergence micropsia (that is, vergence affecting the perceived size of objects) occur in

438 the context of pervasive vergence-accommodation conflict (e.g. the 6.5 dioptres of vergence439 accommodation conflict in Regan et al., 1986). In this context, +/- 1 dioptres of vergence440 accommodation conflict, which is well within the zone of 'clear single binocular vision' (Hoffman 441 et al., 2008), should be entirely permissible. Indeed, it is worth considering that 3 out of the 4 442 contexts I outline in the Introduction in which vergence micropsia has been historically observed 443 (the wallpaper illusion, stereoscopic viewing, telestereoscopic viewing) all rely on inducing much 444 larger vergence / accommodation conflicts than my experiment.

448 Another suggestion that has been put to us is that our results only pertain to objects looming 449 towards us, either because there is something special about looming, or because the visual system 450 in general is task dependent. It is true that my experiment explicitly introduces a physical size 451 change component into the stimulus. Because the stimulus is viewed in darkness and in isolation, 452 the stimulus appears to move towards the observer when it grows in size, and recede from the 453 observer when it reduces in size. This is well documented for objects changing in size when viewed 454 in darkness and in isolation without a change in vergence (González et al., 2010). The argument would have to be that changes in the retinal size are so powerful that they eradicate a vergence size constancy signal that is otherwise effective. But then we have to ask what 457 these other contexts might be. The claim of vergence size constancy is that as an object moves 458 towards us in depth in the real world, the visual system cancels out, at least to some extent, its 459 increasing retinal size. But an object moving towards us at near distances in the real world is almost 460 always accompanied by a change in the retinal image size. So in real world viewing, the vergence 461 size constancy mechanism will almost always be accompanied by a looming cue. 
464 Mon-Williams et al., 1997; Ramsay et al., 2007; Sperandio et al., 2013). Although Quest+ never determine whether the target is increasing or reducing in size.

\section{Gradual Changes in Vergence}

472

473 Another concern relates to the gradual nature of the vergence changes. Perhaps vergence doesn't

effective cue to perceived size when varied more rapidly. Again, we cannot rule out this possibility, but would make four observations. towards your face at $25 \mathrm{~cm}$ whilst counting out "one thousand, two thousand, three thousand, four thousand, five thousand". Whilst the motion in depth is gradual, it is very far from being imperceptible, and we would be concerned if a supposedly important perceptual mechanism were unable to process this very apparent motion in depth.

Whilst it is open to someone to therefore interpret my results as just a critique of Sperandio et al. 
in Sperandio et al. (2013). But if this new account can explain the close to perfect size constancy reported in Sperandio et al. (2013), there is no reason why it couldn't equally explain the close to perfect size constancy reported in other experiments with more rapid eye movements.

494 a chair as we look at a screen, moving backwards and forwards towards the screen at a rate of

$4955 \mathrm{~cm} / \mathrm{s}$ or even less. So what initially looks like an artificial scenario is actually highly relevant to our everyday viewing. gradual change in vergence has removed an important size cue.

504 distance of a target. To maintain that vergence is nonetheless an important absolute distance cue

505 in full cue conditions, one would have to maintain that if I gradually changed the distance of an

506 object in full cue conditions (in the case of Linton, 2020, between $20 \mathrm{~cm}$ and $50 \mathrm{~cm}$ ), participants

507 should be severely compromised in their ability to point to the distance of the object. If they are not, then it is hard to maintain that vergence is both ineffective as a distance cue when gradually manipulated, and yet an important distance cue in full cue conditions. As I note in Linton (2020),

510 "this account risks replacing the ineffectiveness of vergence under my account with the

511 redundancy of vergence under their account." 
515 Another concern is that the eye movements in this experiment are just $25 \mathrm{~cm}$ in depth, and perhaps

516 vergence size constancy is more effective for larger eye movements. But this concern has to be 517 understood in light of the way in which the vergence angle falls off with distance.

518

519

520

521

522

523

524

525

531 Since we only tested convergent eye movements (eye movements from far to near), rather than

532 divergent eye movements (eye movements from near to far), conceptually there is the possibility

533 that vergence size constancy still works in one direction (near to far) but not the other (far to near).

Figure 8. Fall off of vergence angle with distance from Linton (2020). Just as with disparity, the vergence angle falls off as a function of $1 /$ distance $^{2}$.

As Fig. 8 demonstrates, assuming $25 \mathrm{~cm}$ is as close as we look in everyday viewing, then a vergence change from $25 \mathrm{~cm}$ to $50 \mathrm{~cm}$ corresponds to around half the full vergence range from $25 \mathrm{~cm}$ to infinity. If vergence size constancy is not effective in this context, then it cannot be an effective in other contexts (e.g. looking from $50 \mathrm{~cm}$ to $2 \mathrm{~m}$ ) where the change in distance is much greater, but the change in the vergence angle is much less.

\section{Convergent vs Divergent Eye Movements}

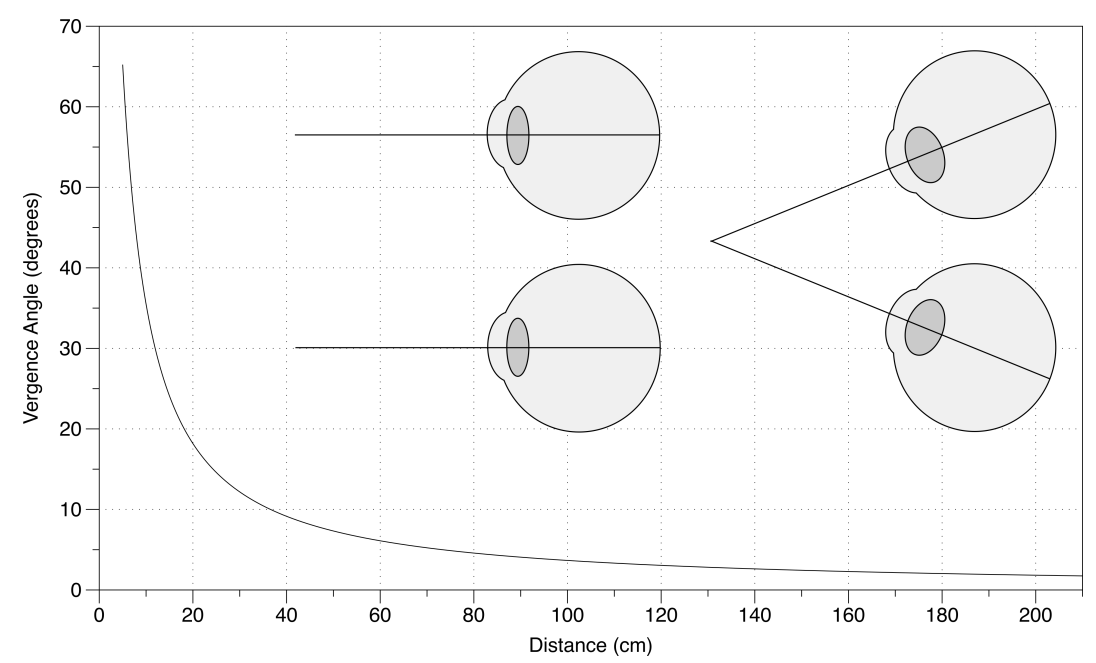


534 However, first, there is no evidence that this is in fact the case. And second, any visual system that increases perceived size when the eyes move from near to far, but doesn't reduce perceived size perceived size of objects as the eyes are moved forwards and backwards in depth. Readers can confirm for themselves that this is not the case.

\section{Vergence Micropsia}

542 If vergence does not affect perceived size, how do I explain the four contexts where vergence

543 micropsia has been reported in the literature, namely 1. the wallpaper illusion (where we cross our

544 eyes when looking at a wallpaper pattern), 2. stereoscopic viewing (where we vary the vergence

545 whilst looking at two identical images in a stereoscope), 3. telestereoscopic viewing (where we

546 effectively increase the interpupillary distance using mirrors), and 4. the Taylor illusion (where an

547 after-image of the hand appears to shrink when we move it towards us).

548 There are two explanations of the wallpaper illusion / stereoscopic viewing. First, the same

549 confounding cues I sought to exclude in this experiment (retinal slip and subjective knowledge

550 about our own eye movements) could be used to cognitively infer a reduced size even if this isn't

551 actually perceived. Second, and more obviously, however, is the fact that the wallpaper illusion

552 and mirror stereoscopes do not control for changes in angular size when we look at a fronto-

553 parallel surface obliquely. This is illustrated by Fig.5 above (and was controlled for in our experiment using OpenGL). Linton (2018) applies this thought to explain vergence micropsia.
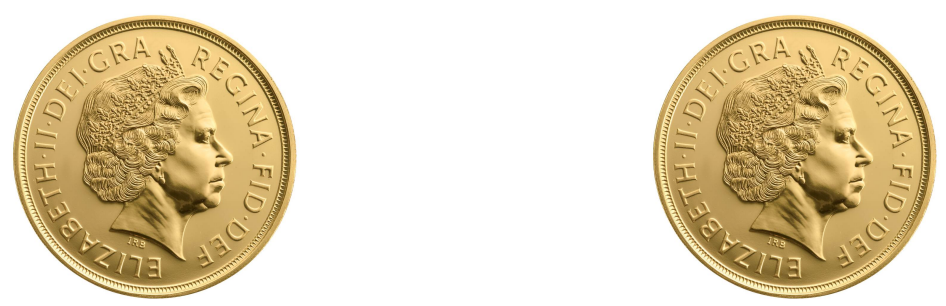
557 Figure 9. Arrange the coins so they are the interpupillary distance apart (roughly $6 \mathrm{~cm})$. Cross fuse

558 the two coins so the right eye looks at the left coin and the left eye looks at the right coin. The central fused coin appears to shrink in size. This is vergence micropsia.

560

561 If you cross-fuse the two coins in Fig.9, the central fused coin appears smaller than when we look

562 at the coins normally. But why does the coin shrink in size if vergence micropsia does not exist?

563 To answer this, we have to understand how the retinal image changes when we cross-fuse.

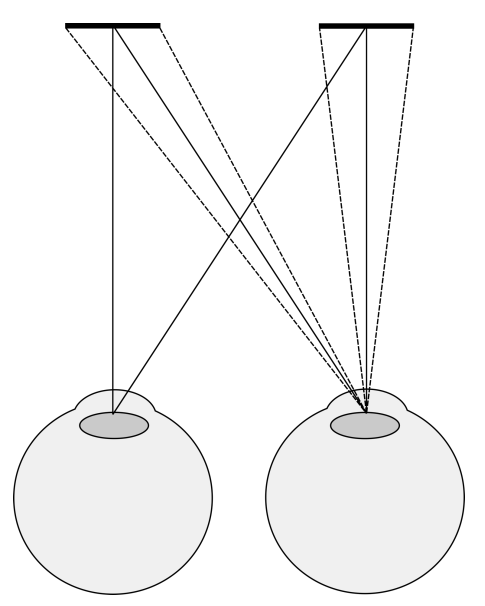

Figure 10. Differences in retinal projections for the left and rights coins in the right eye.

568 As Fig.10 illustrates, when we look at the coins normally the right coin projects a larger retinal image to the right eye than the left eye. Equally the left coin projects a larger retinal image to the left eye than the right eye. Now when we cross-fuse, the fused coin is made up of the smaller retinal image of the left coin in the right eye and the smaller retinal image of the right coin in the left eye, explaining why the fused coin is perceived as reduced in scale. There's an easy test to check whether this is the correct explanation. This account predicts

574 that the flanking monocular coins either side of the fused coin will be made up of the large retinal 575 image of the left coin in the left eye and the large retinal image of the right coin in the right eye, 
so the central fused coin should look smaller than the two monocular flankers. At close viewing

\section{Cognitive Explanation of Vergence Size Constancy}

Let us now turn to the Taylor Illusion as a useful context in which to explore an alternative, purely cognitive, explanation of vergence size constancy. The Taylor illusion (where an after-image of the hand appears to shrink or grow with physical hand movements) is an important paradigm for recent discussions of multisensory integration (Faivre et al., 2017a; Grove et al., 2019). The best current explanation for the Taylor illusion is that it is due (Taylor, 1941; Morrison \& Whiteside, 1984; Mon-Williams et al., 1997) or almost entirely due (Sperandio et al., 2013) to the change in size of the target once subjective knowledge about the fixation distance had been controlled for. since Sperandio et al. (2013) demonstrate that when vergence and hand motion are in conflict, the Taylor illusion follows vergence, and the effect is only marginally reduced in size.

595 their own changing hand and gaze positions. We would suggest that explains why Sperandio et al.

596 (2013) found that vergence affects perceived size when their participants knew about their knowledge about our changing hand or gaze position could influence size constancy. 
to explain an effect that could also be explained as a purely cognitive bias (for further skeptical

is moving towards our face, our hand movements cognitively bias our interpretation of our constant visual experience and we interpret the constant angular size of the after-image as a reduction in physical size.

611 The absence of a change in retinal image size is still a looming cue. The fact that after-images don't change in retinal size, whilst the participant knows that they change in distance (for instance, due

614 the object is shrinking in size, because there is an absence of the attendant increase in retinal size

615 that one would expect. This is an entirely consistent looming-based explanation of the vergence size constancy after-image literature that does not invoke the notion of vergence size constancy. context but not e.g. in the Ames Room where we know that the two people we are seeing are the same size. This is an open question, but note two disanalogies between these two scenarios. First, the Ames Room is about perceived physical size (judging the wrong physical size given the different angular sizes of the people), whilst the Taylor illusion is primarily about perceived angular size (the impression of the hand 'shrinking' or 'growing'). Second, the Taylor illusion occurs over 
628 This purely cognitive interpretation of the Taylor illusion has wide reaching implications for multisensory integration, specifically the integration of vision and hand movements. The Taylor

630 illusion is taken as evidence of multisensory integration at the level of perception. Specifically, that

631 vision "relies on multimodal signals" (Sperandio et al., 2013; Chen et al., 2018) and that "visual 632 consciousness is shaped by the body" (Faivre et al., 2015; Faivre et al., 2017a; Faivre et al., 2017b).

633 But if the integration of proprioception and the retinal image could be purely cognitive in the

634 context of vergence (the major driver of the Taylor illusion in Sperandio et al., 2013), there's no

635 reason why the integration of proprioception and the retinal image in the context of integrating

636 vision and hand movements (the minor driver of the Taylor illusion in Sperandio et al., 2013)

637 couldn't equally be accounted for in purely cognitive terms.

This cognitive approach also suggests a non-perceptual explanation for variants of the

Taylor illusion that appear to demonstrate the integration of vision with the rubber-hand illusion (Faivre et al., 2017a) and tool use (Grove et al., 2019). advanced in the contexts of vision and touch in slant estimation (Hillis et al., 2002; Gepshtein et al., 2005) by Linton (2017), pp.37-38 and pp.65-66, and vision and vestibular cues in self-motion

644 (Fischer \& Kornmüller, 1930; Ash et al., 2011) by Linton (2018).

648 Ever since Trotter et al. (1992) found that the large majority of neurons in the monkey primary visual context (V1) were modulated by vergence, it has been suggested that processing of the 650 vergence signal in V1 plays an important role in size constancy. Further evidence for the vergence 651 modulation of V1 is found by Trotter et al. (1993); Trotter et al. (1996); Dobbins et al. (1998);

652 Trotter \& Celebrini (1999); Cumming \& Parker (1999); Trotter et al. (2004); Cottereau et al. (2014). 653 Cumming \& Parker (1999) found a smaller proportion of neurons in V1 were affected, and to a 
654 less dramatic extent, than in Trotter et al. (1992; 1996). One reason could be the differences in vergence distances tested, but another possibility raised by Cumming \& Parker (1999) is that since 1991; 1995; Quinlan \& Culham, 2007; Culham et al., 2008), and potentially also LGN (Richards, 1968; although this was speculative, and never followed up), as well as early neural network models 661 (Lehky et al., 1990; Pouget \& Sejnowski, 1994) that Trotter et al. (1992) complements.

More recently Chen et al. (2019) have looked at the time course of size constancy, and

663 found that vergence and the retinal image are not integrated during (a) initial processing in V1 ( $\sim 50 \mathrm{~ms})$, but instead during (b) recurrent processing within V1, and/or (c) re-entrant projections from higher-order visual areas (e.g. Gnadt \& Mays, 1991; 1995), both of which are consistent with the $\sim 150 \mathrm{~ms}$ timeframe. This is consistent with Trotter et al. (1992)'s suggestion that whilst

667 vergence responsive neurons encode vergence distance, further computations are required to scale 668 the retinal image, so vergence responsive neurons "constitute an intermediate step in the 669 computation of true depth, as suggested by neural network models [Lehky et al., 1990].”

However this whole line of research, from Trotter et al. (1992) to the present, is prefaced on the fact that "psychophysical data suggest an important role for vergence" (Trotter et al., 1992).

672 And this is what our results in this experiment, and in Linton (2020), question. Taken together, our results in this paper and in Linton (2020) suggest that there is no link between vergence and distance perception (Linton, 2020) or size perception (this paper), and therefore no link between the vergence modulation in V1 (or anywhere else) and distance or size perception. by Trotter et al. (1992; 1996). There are three possibilities: 
suggested is that distance is extracted from vergence in order to scale binocular disparities for our perception of 3D shape (Wallach \& Zuckerman, 1963), and that errors in this mechanism are responsible for distortions of visual shape (Johnston, 1991). This will be the focus of future experimental work, although we would be surprised if distance from vergence was used to scale binocular disparities whilst failing to scale size and distance themselves. to vergence that could equally be explained by changes in the retinal image. Cumming \& Parker 687 (1999) raise the prospect of vergence insufficiency leading to changes in retinal disparity. Another 688 possibility is that the results in Trotter et al. (1992; 1996) simply reflect changes in vertical disparity with distance, since Trotter et al. $(1992 ; 1996)$ change the distance of the display, not vergence per se. So the vergence modulations in V1 might simply be artifacts. visually identical targets (Saleem et al., 2018). So the vergence modulations of V1, if they do exist, could equally reflect the participant's own purely cognitive knowledge about their changing gaze position, even though this has no effect on their visual experience.

Of the four instances of vergence size constancy we discussed in the Introduction, alternative explanations of (a) the wallpaper illusion and (b) stereoscopic viewing have been provided in

704 Section 7, whilst an alternative explanation of (c) the Taylor illusion is provided in Section 8. That only leaves (d) telestereoscopic viewing to be explained. This is when the interpupillary distance 
of the eyes is increased using mirrors, leading to the impression that the world has been

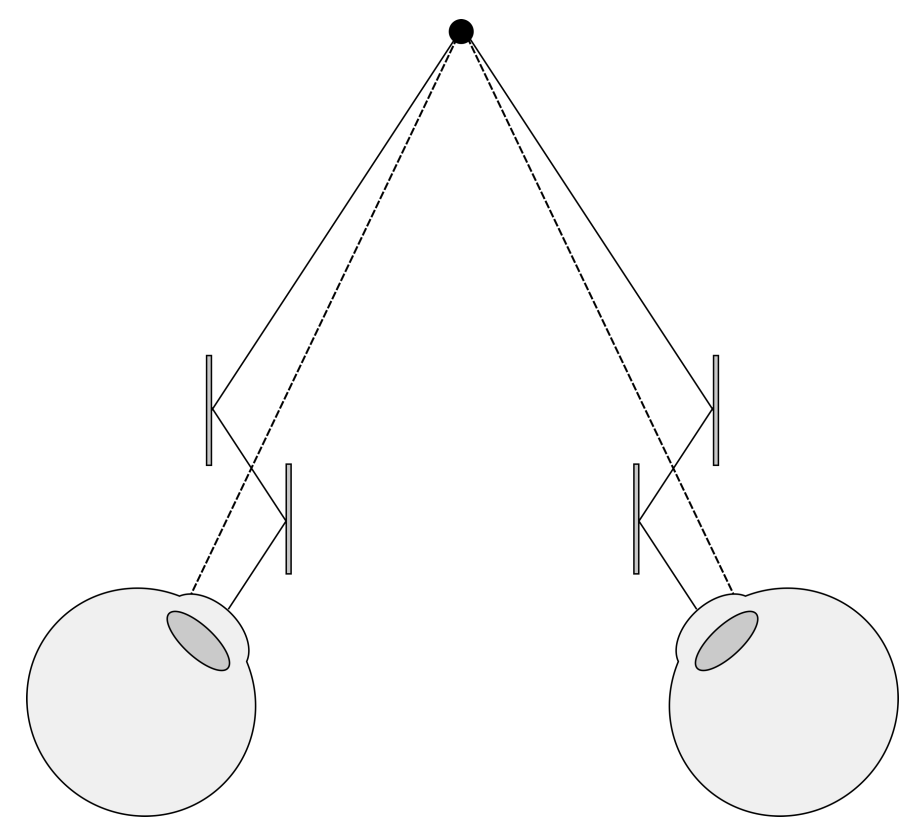

711 Figure 11. Telestereoscopic viewing. Mirrors alter the path of light to the eyes. In order to view

712 the same point in space, the eyes now have to rotate more (as indicated by the solid line) than they ordinarily would (as indicated by the dotted line).

715 However, our results in this paper challenge this account.

An alternative explanation for this effect, and potentially the micropsia effects in the wallpaper illusion and stereoscopic viewing (although not the Taylor illusion), are changes in vertical disparities. Although Rogers (2009; 2011) appeals to vertical disparities as well as vergence to explain telestereoscopic viewing, we are skeptical of this explanation.

The initial promise of vertical disparities was that you could take any three points in the

721 scene (and potentially just two), and determine the geometry and viewing distance of the scene

722 (Longuet-Higgins, 1982) (see also Mayhew, 1982; Mayhew \& Longuet-Higgins, 1982). However, 723 there's no evidence the visual system can achieve this with such a limited number of points, and 
the emphasis soon shifted (in Gillam \& Lawergren, 1983) to the gradient of vertical disparities across a fronto-parallel surface. Rogers (2017) explains the contemporary vertical disparity horizontal gradient of the ratio of the vertical sizes in the two eyes and this varies with viewing distance." But there are four concerns with account:

First, telestereoscopic viewing should not affect our perception of size and distance under

730 the classic Longuet-Higgins (1982) account, since in the process of estimating egocentric distance

731 this account also estimates the interpupillary distance and vergence angle. Put simply, whether our 732 eyes are far apart and rotated a lot, or close together and rotated a little, so long as they are fixated on the same point in physical space, the approach in Longuet-Higgins (1982) should give exactly the same egocentric distance, and therefore exactly the same perceived scale. periphery. But even the results for a $60^{\circ}$ surface are questionable. Vienne et al. (2016) investigated how vertical disparities could improve the distance perception of a cylinder in front of a $60^{\circ}$

740 background. However, first, subjects performed no better, and potentially performed worse, with 741 the $60^{\circ}$ background present than without it. Second, whilst increasing the vertical disparities of the

742 background did change the apparent distance of the cylinder, this was largely because participants changed their previous judgements about the cylinder's distance when the background's vertical disparities were undistorted. Had participants made consistent judgements about the same

747 becomes hard to maintain that vertical disparities provide an effective absolute distance cue. 
observers differed in the way they used numbers to indicate absolute distances", and so distances underwent a normalisation and scaling process. the sharp fall-off of vertical disparities with distance for a $60^{\circ} \times 60^{\circ}$ surface in Vienne et al., 2016, Fig.1c), and (3) take up at least $30^{\circ}$ (and arguably $60^{\circ}-70^{\circ}$ ) of the visual field. Since such surfaces are almost never encountered in natural viewing conditions, this cannot be how we experience visual scale. Theoretically the results in Rogers \& Bradshaw (1995) and Vienne et al. (2016) could support a broader principle, but as Rogers \& Bradshaw (1995) note: "Whether the visual system extracts the vertical disparities of individual points or the gradient of VSRs over a surface is an empirical question for which there is no clear answer at present." $70^{\circ}$ of the visual field. This can't explain how telestereoscopic viewing can change the perceived and Fig.13. Looking at them through red-blue glasses with one eye open, they look like normal 766 photos. But as soon as you view them through red-blue glasses with both eyes open, you get the 767 immediate impression that we are "not looking at the natural landscape itself, but a very exquisite 768 and exact model of it, reduced in scale" (Helmholtz, 1866, p.312). Whatever explains the miniaturisation effect of telestereoscopic photographs likely explains the miniaturisation effect of telestereoscopic viewing in the real world, and yet large angular sizes are not required for telestereoscopic photographs to be effective. 
bioRxiv preprint doi: https://doi.org/10.1101/2020.02 23 961649; this version posted June 20, 2021. The copyright holder for this preprint (which was not certified by peer review) is the author/funder, who has granted bioRxiv a license to display the preprint in perpetuity. It is made available under aCC-BY 4.0 International license.

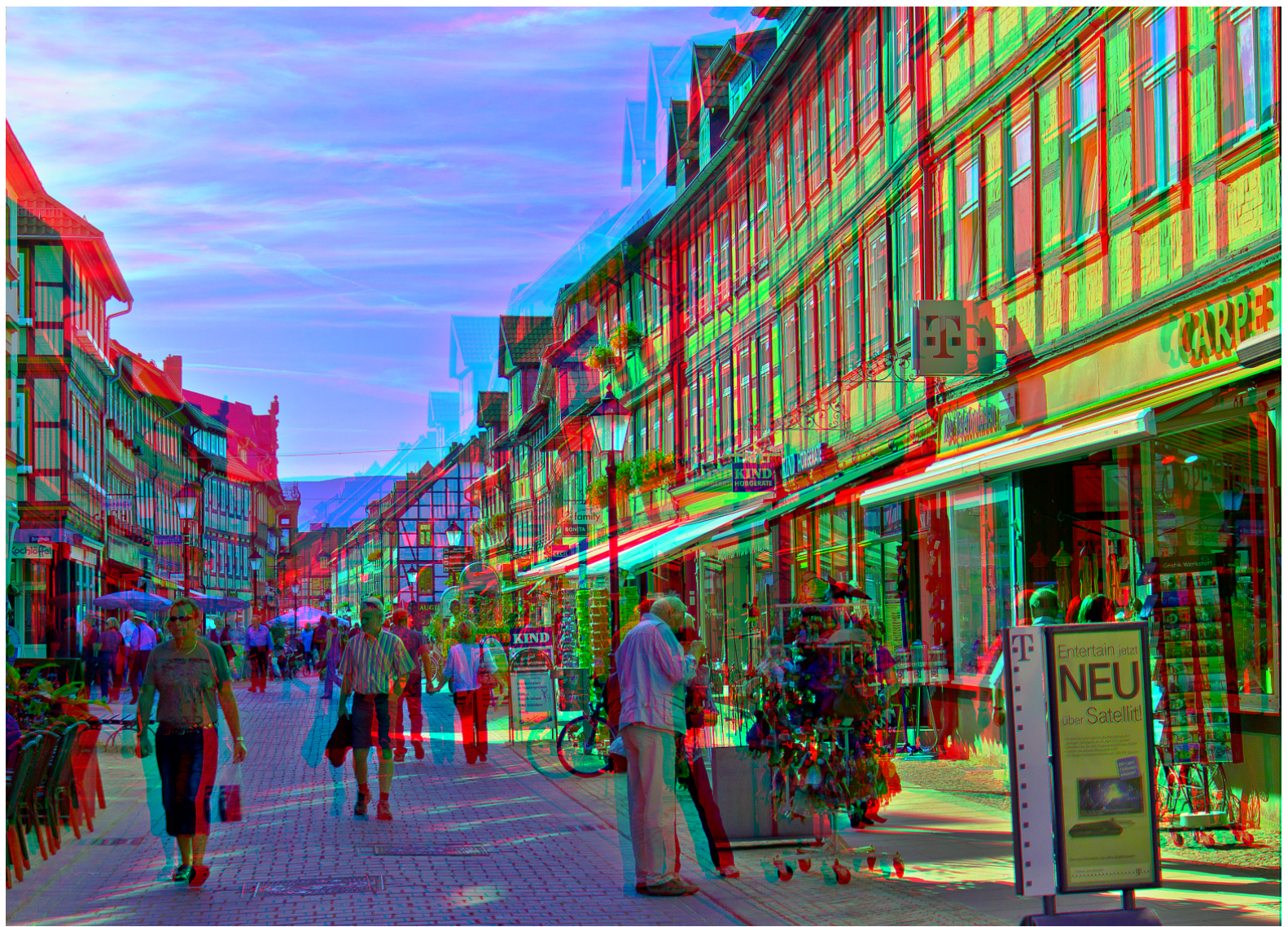

775 Figure 12. 'Wernigerode Boulevard' (2011) by Sasha Becher. (C) Sasha Becher. Used with

776 permission from:

777 https://www.flickr.com/photos/stereotron/6597314627/in/album-72157612377392630/

778 For more of Sasha Becher's telestereoscopic images please see: 
bioRxiv preprint doi: https://doi.org/10.1101/2020.02 23.961649; this version posted June 20, 2021. The copyright holder for this preprint (which was not certified by peer review) is the author/funder, who has granted bioRxiv a license to display the preprint in perpetuity. It is made available under aCC-BY 4.0 International license.

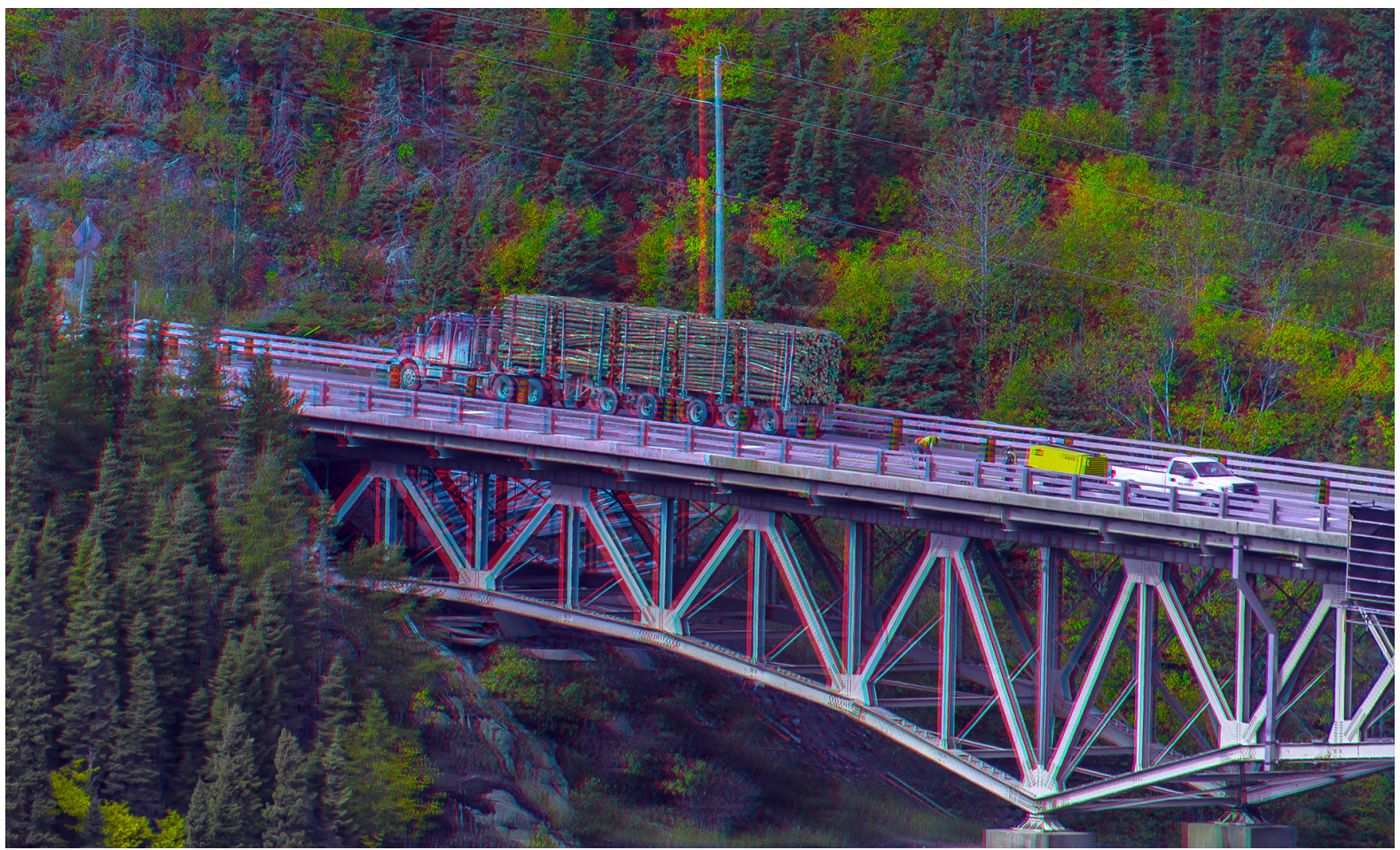

Figure 13. 'Trans-Canada Highway @ Neyes National Park’ (2014) by Sasha Becher. C Sasha

Becher. Used with permission from:

https://www.flickr.com/photos/stereotron/28817920100/in/album-72157612377392630/

784 For more of Sasha Becher's telestereoscopic images please see:

\section{https://www.flickr.com/photos/stereotron/}

787 Instead of vergence or vertical disparities, in Linton (2018a) I advance a third distinct explanation

788 for the change in scale experienced in telestereoscopic viewing based on horizontal disparities. The

789 argument begins from the premise that this is the only remaining parameter that is manipulated in

790 telestereoscopic viewing apart from vergence and vertical disparities. Horizontal disparities are

791 typically thought of merely as an affine depth cue (not even a relative depth cue) until they are

792 scaled by an absolute distance cue, typically thought to be vergence (Wallach \& Zuckerman, 1963;

793 Johnston, 1991). The reason for this is that binocular disparities fall off with $1 /$ distance $^{2}$, and so

794 in order to extract relative depth (which is a relationship in terms of $1 /$ distance not $1 /$ distance $^{2}$ )

795 we need to know the viewing distance. So, on this account, distance from vergence provides us 
with perceived stereo depth (Johnston, 1991): 'Distance $\rightarrow$ Stereo Depth'. My argument in

797 (Linton, 2018a) seeks to invert this relationship (known as 'depth constancy'), to instead go from

First, on this account, there is no scaling of binocular disparity using vergence, and

800 therefore no 'depth constancy'. Whilst Johnston (1991) found some evidence of 'depth constancy',

801 this was not tested in the controlled blackout conditions of Linton (2020) or this paper. Under this

802 alternative account, perceived depth simply reflects binocular disparity that falls off with

$8031 /$ distance $^{2}$. This will be the subject of future empirical investigation.

804 Second, under this account, we are unconsciously very sensitive to the way in which 805 perceived depth falls off with distance. What I describe as "a cognitive association between (a) vivid stereo depth and (b) closer distances (reflecting our experience of an environment where

807 disparity falls-off with distance ${ }^{2}$ ") in Linton (2018a). Put simply, we only ever experience the vivid

808 stereo depth we experience in Figures 12 and 13 when we view a scene up close, and so we interpret 809 it as miniature (Linton, 2020b).

810 Whilst vivid stereo depth equates to near distances, flat stereo depth could equate to 'far 811 away' or 'up close and flat', so assumptions about scene geometry will often be necessary. Our 812 interpretation of the relationship between stereo depth and distance is informed by natural scene 813 statistics (Linton, 2020b), enabling us to make appropriate assumptions.

814 The relationship between stereo depth and distance would be more informative if we could 815 compare the perceived geometry of the scene (depth from disparity) with the actual geometry of 816 the scene. So, in Figures 12 and 13, we might additionally infer that the accentuated stereo-depth 817 in Figures 12 and 13 is only consistent with the geometry of the scene if the scene is being viewed 818 up close; i.e., if the scene is miniature (Linton, 2020b). If we do, it may be that we recognise the 819 scene as of a certain familiar kind. Or it may be that we rely on pictorial cues, which are 820 comparatively distance invariant (albeit subject to perspective distortions / foreshortening: 
821 Tehrani et al., 2016), and which are unaffected by telestereoscopic viewing (which increases

822 binocular disparity without reducing viewing distance).

a pictorial sense are processed after stereo depth has been perceptually resolved. For instance, you

827 can embed a 2D line drawing of a cube within a random dot stereogram. The line drawing only

828 emerges after the stereo depth has been perceptually resolved. But you can still recognise it as a

829 2D line drawing of a cube. So you're interpreting the shape of the cube using pictorial cues, such

830 as perspective, much like any $2 \mathrm{D}$ line drawing. But it would be a mistake to suggest that this

831 necessarily implies that what you are relying on are monocular cues because they don't exist.

832 Similarly, you can imagine viewing a face in a random dot stereogram. The face might be

833 accentuated or reduced in depth, but you'd still be able to understand it as a face, and therefore

834 interpret it as being accentuated or reduced in depth even though there are no monocular cues.

835 Third, we claim that the relationship between accentuated stereo depth (i.e. accentuated

$8363 \mathrm{D}$ shape) and visual scale is merely a post-perceptual cognitive association. What does this mean?

837 So far as our visual experience is concerned, all that is being manipulated with telestereoscopic

838 viewing is our perception of 3D shape. An illustration of this is provided with Fig.12 and Fig.13.

839 Close one eye and we don't have the apparent miniaturisation in scale that we do with binocular

840 vision. And yet what changes between monocular and binocular viewing? First, the angular size of

841 the objects in the scene does not appear to change in any dramatic sense, so we cannot attribute

842 to the dramatic change in perceived scale to a dramatic change in perceived angular size. Second,

843 the distance of an object in the image does not appear to change dramatically when we fixate on

844 it and close one eye. So there is no sense that our perception of (a) size or (b) distance changes

845 dramatically as we fixate on an object in the scene and open and close one eye. Instead, the defining

846 change in our visual experience as is the change in the perceived 3D shape of the scene. 
848 But that would be a mistake. What telestereoscopic viewing demonstrates is that binocular cues

849 dominate all other cues to absolute size and distance. In telestereoscopic viewing all other cues to

850 absolute distance in the real world are maintained, and yet our impression of visual scale varies

851 dramatically with the manipulation of the inter-pupillary distance using mirrors. Instead of

852 interpreting our inter-pupillary distance as changing, we attribute this change to the scene itself,

853 and see it as miniaturised. Whatever explains why we see the world as the wrong size when

854 binocular cues are wrong (in telestereoscopic viewing) also explains why we see the world as the

855 right size when binocular cues are correct (in ordinary binocular viewing).

856 If this is the correct interpretation of telestereoscopic viewing, then our results suggests

857 that visual scale is much more reliant on cognitive influences than previously thought. First,

858 because our results challenge the suggestion that size and distance are triangulated using vergence.

859 Second, because our alternative explanation of binocular scale perception in telestereoscopic

860 viewing is entirely cognitive in nature. Our results are consistent with our argument in Linton

861 (2017; 2018) that visual scale is based solely on higher level cognitive processes, where we extend

862 Gogel (1969)'s and Predebon (1992)'s observations about familiar size to argue that visual scale

863 itself is a purely cognitive process.

865 12. Development of Size Constancy

867 One objection to our account is that infants $1.5-2$ months of age can apparently respond to the 868 physical, and not just the retinal, size of objects (Bower, 1965; Granrud, 1987; Slater et al., 1990).

869 According to this objection, this speaks against a cognitive explanation. However, we have good

870 reason to be cautious of the claims in this literature. First, Bower (1965) found no benefit of

871 binocular vision on infant size constancy, grounding his account in motion parallax instead. This

872 should immediately alert us that this literature is missing something important. Second, even on 
873 motion parallax, Bower admitted that infants could simply be responding to changes in the

874 stimulus with head movements, rather than perceived size. Third, a counterpoint to this literature

875 is that those with their sight restored after early blindness often experience gross errors in their

876 distance judgements (Gregory \& Wallace, 1963; Šikl et al., 2013). Fourth, whilst it is merely

877 anecdotal, Helmholtz (1866)'s recollection of his own gross failures of size constancy as a child

878 (Vol.3, p.283) inspired his whole account of inferential size and distance perception.

879

880 Conclusion

881

882 Vergence is thought to provide an essential signal for size constancy. We tested vergence size constancy for the first time without confounding cues, and found no evidence that eye movements make any contribution to perceived size. We explore a number of alternative explanations for these results. Whilst we cannot definitively exclude these alternatives, we conclude that the most

886 plausible interpretation of our results is that vergence does not contribute to size perception, 887 complimenting previous results (Linton, 2020) that also suggest that vergence does not contribute 888 to distance perception. If this is the correct interpretation, this work has three important 889 implications. First, it suggests that our impression of visual scale is much more reliant on cognitive 890 processing than previously thought. Second, it leads us to question whether the vergence 891 modulation of neurons in V1 reported in the literature really contributes to our impression of 892 visual scale. Third, it leads us to question whether the multisensory integration reported in the context of the retinal image with proprioceptive cues from the hand is better understood in terms

894 of observers having subjective knowledge about their hand and gaze position. 
898 This research was conducted under the supervision of Christopher Tyler and Simon Grant. We

899 thank Salma Ahmad, Mark Mayhew, and Deanna Taylor, for fitting the contact lenses, and Jugjeet

900 Bansal, Priya Mehta, and the staff of the CitySight clinic for their assistance. We thank Joshua

901 Solomon, Matteo Lisi, Byki Huntjens, Michael Morgan, Chris Hull, and Pete Jones for their advice.

902 We thank audiences at the Applied Vision Association (2019), the British Machine Vision

903 Association's '3D worlds from 2D images in humans and machines' meeting (2020):

904 https://youtu.be/6P3EYCEn52A and the (Virtual) Vision Sciences Society (2020):

905 https://osf.io/tb3un/ / http://youtu.be/VhpYjPj5Q80 where this work was presented, as well

906 as audiences at the Association for the Scientific Study of Consciousness (2019) where the

907 argument about telestereoscopic viewing was presented: https://osf.io/9ry3s/. We thank Scott

908 Murray for allowing me to reproduce Fig.1, and Sascha Becher for allowing me to reproduce Fig.12

909 and Fig.13. We also thank the three referees and the two editors for their very valuable comments

910 on the paper.

911

912 Open Practice Statement

913

914 Code for running the experiment, and all the data and analysis scripts, are accessible in an open

915 access repository: https://osf.io/5nwaz/ 


\section{References}

918 Adams, O. S. (1955). Stereogram decentration and stereo-base as factors influencing the apparent size of stereoscopic pictures. The American Journal of Psychology, 68(1), 54-68.

Ash, A., Palmisano, S., \& Kim, J. (2011). Vection in Depth during Consistent and Inconsistent Multisensory Stimulation. Perception, 40(2), 155-174. https://doi.org/10.1068/p6837

Balaban, C. D., Kiderman, A., Szczupak, M., Ashmore, R. C., \& Hoffer, M. E. (2018). Patterns of Pupillary Activity During Binocular Disparity Resolution. Frontiers in Neurology, 9. https://doi.org/10.3389/fneur.2018.00990

Biersdorf, W. R., Ohwaki, S., \& Kozil, D. J. (1963). The Effect of Instructions and Oculomotor Adjustments on Apparent Size. The American Journal of Psychology, 76(1), 1-17. JSTOR. https://doi.org/10.2307/1419994

Bishop, P. O. (1989). Vertical Disparity, Egocentric Distance and Stereoscopic Depth Sciences, 237(1289), 445-469.

Bower, T. G. R. (1965). Stimulus variables determining space perception in infants. Science, 149(Whole No. 3679), 88-89. https://doi.org/10.1126/science.149.3679.88

Brainard, D. H. (2017). mQUESTPlus: A Matlab implementation of QUEST+. https://github.com/brainardlab/mQUESTPlus

Brenner, E., \& van Damme, W. J. (1998). Judging distance from ocular convergence. Vision Research, 38(4), 493-498.

Brewster, D. (1844). On the knowledge of distance given by binocular vision. Transactions of the Royal Society of Edinburgh, 15, 663-674.

939

Bross, M. (2000). Emmert's law in the dark: Active and passive proprioceptive effects on positive visual afterimages. Perception, 29(11), 1385-1391. https://doi.org/10.1068/p3038

941 Carey, D. P., \& Allan, K. (1996). A motor signal and "visual" size perception. Experimental Brain 
943 Chen, J., Sperandio, I., \& Goodale, M. A. (2018). Proprioceptive Distance Cues Restore Perfect Size Constancy in Grasping, but Not Perception, When Vision Is Limited. Current Biology: CB, 28(6), 927-932.e4. https://doi.org/10.1016/j.cub.2018.01.076

946 Chen, J., Sperandio, I., Henry, M. J., \& Goodale, M. A. (2019). Changing the Real Viewing Distance Reveals the Temporal Evolution of Size Constancy in Visual Cortex. Current Biology, 29(13), 2237-2243.e4. https://doi.org/10.1016/j.cub.2019.05.069

949 Choe, K. W., Blake, R., \& Lee, S.-H. (2016). Pupil size dynamics during fixation impact the accuracy and precision of video-based gaze estimation. Vision Research, 118, 48-59.

952 Combe, E., \& Wexler, M. (2010). Observer Movement and Size Constancy. Psychological Science, 21(5), 667-675. JSTOR.

Cottereau, B., Durand, J.-B., Vayssière, N., \& Trotter, Y. (2014). The influence of eye vergence on retinotopic organization in human early visual cortex. Perception, ECVP Abstracts 2014, 81. https://doi.org/10.1177/03010066140430S101, poster available at https://f1000research.com/posters/1096674

Culham, J., Gallivan, J., Cavina-Pratesi, C., \& Quinlan, D. (2008). FMRI investigations of reaching and ego space in human superior parieto-occipital cortex. In Embodiment, Egospace and Action (pp. 247-274).

962

Cumming, B. G., Johnston, E. B., \& Parker, A. J. (1991). Vertical Disparities and Perception of Three-Dimensional Shape. Nature; London, 349(6308), 411-413.

963 Cumming, B. G., \& Parker, A. J. (1999). Binocular Neurons in V1 of Awake Monkeys Are Selective for Absolute, Not Relative, Disparity. Journal of Neuroscience, 19(13), 5602-5618. https://doi.org/10.1523/JNEUROSCI.19-13-05602.1999

966 Descartes, R. (1637). Dioptrique (Optics). In J. Cottingham, R. Stoothoff, \& D. Murdoch (Eds.), The 
968 Dobbins, A. C., Jeo, R. M., Fiser, J., \& Allman, J. M. (1998). Distance Modulation of Neural Activity in the Visual Cortex. Science, 281(5376), 552-555.

970 https://doi.org/10.1126/science.281.5376.552

971 Drewes, J., Zhu, W., Hu, Y., \& Hu, X. (2014). Smaller Is Better: Drift in Gaze Measurements due to Pupil Dynamics. PLOS ONE, 9(10), e111197. https://doi.org/10.1371/journal.pone.0111197

974 Emmert, E. (1881). Größenverhältnisse der Nachbilder. Klinische Monatsblätter Für Augenheilkunde Und Für Augenärztliche Fortbildung, 19, 443-450.

976 Enright, J. T. (1989). Enright JT (1989). "The eye, the brain and the size of the moon: Toward a unified oculomotor hypothesis for the moon illusion”. In Hershenson, Maurice (ed.). The Moon illusion. Hillsdale, N.J: L. Erlbaum Associates. Pp. 59-121. In M.

979 Hershenson, The Moon Illusion (pp. 59-121). L. Erlbaum Associates. eye: A call for a multisensory study of subjective experience. Neuroscience of Consciousness, 2017(1). https://doi.org/10.1093/nc/nix003

Faivre, N., Dönz, J., Scandola, M., Dhanis, H., Ruiz, J. B., Bernasconi, F., Salomon, R., \& Blanke, O. (2017a). Self-Grounded Vision: Hand Ownership Modulates Visual Location through Cortical $\beta$ and $\gamma$ Oscillations. Journal of Neuroscience, 37(1), 11-22. https://doi.org/10.1523/JNEUROSCI.0563-16.2016

Faivre, N., Salomon, R., \& Blanke, O. (2015). Visual consciousness and bodily selfconsciousness. Current Opinion in Neurology, 28(1), 23-28. https://doi.org/10.1097/WCO.0000000000000160

990 Firestone, C., \& Scholl, B. J. (2016). Cognition does not affect perception: Evaluating the evidence for "top-down" effects. The Behavioral and Brain Sciences, 39, e229. https://doi.org/10.1017/S0140525X15000965 
993 Fischer, M. H., \& Kornmüller, A. E. (1930). Optokinetic-Induced Motion Perception and

995 Fodor, J. A. (1983). The Modularity of Mind: An Essay on Faculty Psychology. MIT Press.

996 Frank, H. (1930). Ueber den Einfluss inadaquater Konvergenz und Akkommodation auf die Sehgrosse. Psychol. Forsch., 13, 135-144.

998 Gepshtein, S., Burge, J., Ernst, M. O., \& Banks, M. S. (2005). The combination of vision and touch depends on spatial proximity. Journal of Vision, 5(11), 7-7. https://doi.org/10.1167/5.11.7

Gillam, B., \& Lawergren, B. (1983). The induced effect, vertical disparity, and stereoscopic theory. Perception \& Psychophysics, 34(2), 121-130. https://doi.org/10.3758/bf03211336

Gnadt, J. W., \& Mays, L. E. (1991). Depth tuning in area LIP by disparity and accommodative cues. Soc Neurosci Abs, 17, 1113.

1006

Gnadt, J. W., \& Mays, L. E. (1995). Neurons in monkey parietal area LIP are tuned for eye-

1008 Goethe, J. W. von. (1810). Zur Farbenlehre. in der J.G. Cotta'schen Buchhandlung.

1009 Gogel, W. C. (1962). The Effect of Convergence on Perceived Size and Distance. The Journal of Psychology, 53(2), 475-489. https://doi.org/10.1080/00223980.1962.9916591

1011 Gogel, W. C. (1969). The Sensing of Retinal Size. Vision Research, 9, 1079-1094.

1012 González, E. G., Allison, R. S., Ono, H., \& Vinnikov, M. (2010). Cue conflict between disparity 1013 change and looming in the perception of motion in depth. Vision Research, 50(2), 136143. https://doi.org/10.1016/j.visres.2009.11.005

1015 Goodale, M. A. (2020). How big is that banana? Differences in size constancy for perception and action. https://drive.google.com/file/d/1LiOvNebMXRwAB6M53_XIc34vzP4qPWW9/view

1017 Granrud, C. E. (1987). Size constancy in newborn human infants [ARVO Abstract]. Investigative Ophthalmology and Visual Science, 28(Supplement), 5. 
1019 Gregory, R. L., \& Wallace, J. G. (1963). Recovery from early blindness. Experimental Psychology Society Monograph.

1021 Gregory, R. L., Wallace, J. G., \& Campbell, F. W. (1959). Changes in the size and shape of visual after-images observed in complete darkness during changes of position in space. Quarterly Journal of Experimental Psychology, 11(1), 54-55. https://doi.org/10.1080/17470215908416288

1025 Grove, C., Cardinali, L., \& Sperandio, I. (2019). Does Tool-Use Modulate the Perceived Size of an Afterimage During the Taylor Illusion? [Abstract ECVP Leuven 2019]. Perception, 48, 181.

1029

1030

Heinemann, E. G., Tulving, E., \& Nachmias, J. (1959). The effect of oculomotor adjustments on

Helmholtz, H. (1857). Das Telestereoskop. Annalen Der Physik, 178(9), 167-175. https://doi.org/10.1002/andp.18571780907

Helmholtz, H. (1866). Handbuch der Physiologischen Optik, Vol.III (translated by J. P. C. Southall 1925 Opt. Soc. Am. Section 26, reprinted New York: Dover, 1962).

Helmholtz, P. H. (1858). II. On the telestereoscope. The London, Edinburgh, and Dublin Philosophical Magazine and Journal of Science, 15(97), 19-24. https://doi.org/10.1080/14786445808642433

Hermans, T. G. (1937). Visual size constancy as a function of convergence. Journal of Experimental Psychology, 21(2), 145-161. https://doi.org/10.1037/h0058367

Hermans, T. G. (1954). The relationship of convergence and elevation changes to judgments of size. Journal of Experimental Psychology, 48(3), 204-208. https://doi.org/10.1037/h0059355 Mandatory Fusion Within, but Not Between, Senses. Science, 298(5598), 1627-1630. https://doi.org/10.1126/science.1075396 
1045 Hoffman, D. M., Girshick, A. R., Akeley, K., \& Banks, M. S. (2008). Vergence-accommodation conflicts hinder visual performance and cause visual fatigue. Journal of Vision, 8(3), 33-33.

1047 https://doi.org/10.1167/8.3.33

1048 Hooge, I. T. C., Hessels, R. S., \& Nyström, M. (2019). Do pupil-based binocular video eye trackers reliably measure vergence? Vision Research, 156, 1-9. https://doi.org/10.1016/j.visres.2019.01.004

1051

Howard, I. P. (2012). Perceiving in Depth, Volume 3: Other Mechanisms of Depth Perception. Oxford

1053 Johnston, E. B. (1991). Systematic distortions of shape from stereopsis. Vision Research, 31(7), 1351-1360. https://doi.org/10.1016/0042-6989(91)90056-B

1055

Judd, C. H. (1897). Some facts of binocular vision. Psychological Review, 4(4), 374-389.

1056 https://doi.org/10.1037/h0073701

1057

Kepler, J. (1604). Paralipomena to Witelo. In W. H. Donahue (Trans.), Optics: Paralipomena to Witelo and Optical Part of Astronomy. Green Lion Press, 2000.

Kleiner, M., Brainard, D., \& Pelli, D. (2007). Kleiner M, Brainard D, Pelli D, 2007, “What's new in Psychtoolbox-3?” Perception 36 ECVP Abstract Supplement. Perception, 36(ECVP

1062 Kohly, R. P., \& Ono, H. (2002). Fixating on the wallpaper illusion: A commentary on "The role of vergence in the perception of distance: A fair test of Bishop Berkeley's claim” by

1065 Komoda, M. K., \& Ono, H. (1974). Oculomotor adjustments and size-distance perception. Perception \& Psychophysics, 15(2), 353-360. https://doi.org/10.3758/BF03213958

1067 Konrad, R., Angelopoulos, A., \& Wetzstein, G. (2019). Gaze-Contingent Ocular Parallax 
bioRxiv preprint doi: https://doi org/10.1101/2020.02.23 961649; this version posted June 20, 2021. The copyright holder for this preprint (which was not certified by peer review) is the author/funder, who has granted bioRxiv a license to display the preprint in perpetuity. It is made available under aCC-BY 4.0 International license.

1069 Lakens, D., Scheel, A. M., \& Isager, P. M. (2018). Equivalence Testing for Psychological

1070 Research: A Tutorial. Advances in Methods and Practices in Psychological Science, 1(2), 259-269.

1071 https://doi.org/10.1177/2515245918770963

1072 Lehky, S., Pouget, A., \& Sejnowski, T. (1990). Neural Models of Binocular Depth Perception. Cold Spring Harbor Symposia on Quantitative Biology, 55, 765-777. https://doi.org/10.1101/SQB.1990.055.01.072

1075 Leibowitz, H., Brislin, R., Perlmutrer, L., \& Hennessy, R. (1969). Ponzo Perspective Illusion as a Manifestation of Space Perception. Science, 166(3909), 1174-1176.

1077 https://doi.org/10.1126/science.166.3909.1174

Leibowitz, H., \& Moore, D. (1966). Role of changes in accommodation and convergence in the perception of size. Journal of the Optical Society of America, 56(8), 1120-1129.

1080 https://doi.org/10.1364/JOSA.56.001120

1081 Leibowitz, H. W., Shiina, K., \& Hennessy, R. T. (1972). Oculomotor adjustments and size constancy. Perception \& Psychophysics, 12(6), 497-500. https://doi.org/10.3758/BF03210943

1084 Lie, I. (1965). Convergence as a cue to perceived size and distance. Scandinavian Journal of Psychology, 6(4), 109-116. https://doi.org/10.1111/j.1467-9450.1965.tb01059.x

1086 Linton, P. (2017). The Perception and Cognition of Visual Space. Palgrave.

1087 Linton, P. (2019). Would Gaze-Contingent Rendering Improve Depth Perception in Virtual and Augmented Reality? https://arxiv.org/abs/1905.10366v1

1089 Linton, P. (2020a). Does vision extract absolute distance from vergence? Attention, Perception, \& Psychophysics, 82(6), 3176-3195. https://doi.org/10.3758/s13414-020-02006-1

1091 Linton, P. (2020b, January 30). Does Human Vision Triangulate Absolute Distance. https://www.youtube.com/watch?v=6P3EYCEn52A

1093 Linton, P. (2021). V1 as an Egocentric Cognitive Map. PsyArXiv.

1094 https://doi.org/10.31234/osf.io/2sv9m 
Linton, P. (2018a). Do We See Scale? https://www.biorxiv.org/content/10.1101/371948v1

1096

Locke, J. (1849). XXV. On single and double vision produced by viewing objects with both eyes;

1097 and on an optical illusion with regard to the distance of objects. The London, Edinburgh, and Dublin Philosophical Magazine and Journal of Science, 34(228), 195-201.

1099 https://doi.org/10.1080/14786444908646207

Locke, N. M. (1938). Some Factors in Size-Constancy. The American Journal of Psychology, 51(3), 514-520. JSTOR. https://doi.org/10.2307/1416151

1102 Longuet-Higgins, H. C. (1982). The Role of the Vertical Dimension in Stereoscopic Vision. Perception, 11(4), 377-386. https://doi.org/10.1068/p110377

1104 Lou, L. (2007). Apparent Afterimage Size, Emmert's Law, and Oculomotor Adjustment. Perception, 36(8), 1214-1228. https://doi.org/10.1068/p5513

1106 Marin, F., Rohatgi, A., \& Charlot, S. (2017). WebPlotDigitizer, a polyvalent and free software to extract spectra from old astronomical publications: Application to ultraviolet spectropolarimetry. ArXiv:1708.02025 [Astro-Ph]. http://arxiv.org/abs/1708.02025

1109 Mayhew, J. (1982). The Interpretation of Stereo-Disparity Information: The Computation of $1110 \quad$ Surface Orientation and Depth. Perception, 11(4), 387-407.

1111 https://doi.org/10.1068/p110387

1112 Mayhew, J. E. W., \& Longuet-Higgins, H. C. (1982). A computational model of binocular depth 1113 perception. Nature, 297(5865), 376-378. https://doi.org/10.1038/297376a0

1114 McCready, D. W. (1965). Size-distance perception and accommodation-convergence micropsia-A critique. Vision Research, 5(4), 189-206. https://doi.org/10.1016/0042-

1117 Meyer, H. (1842). Ueber einige Täuschungen in der Entfernung u. Grösse der Gesichtsobjecte. 
1119 Meyer, H. (1852). Ueber die Schätzung der Grösse und der Entfernung der Gesichtsobjecte aus der Convergenz der Augenaxen. Annalen Der Physik, 161(2), 198-207. https://doi.org/10.1002/andp.18521610204

Millard, A. S., Sperandio, I., \& Chouinard, P. A. (2020). The contribution of stereopsis in Emmert's law. Experimental Brain Research, 238(4), 1061-1072. https://doi.org/10.1007/s00221-020-05747-5

Mon-Williams, M., \& Tresilian, J. R. (1999). Some Recent Studies on the Extraretinal Contribution to Distance Perception. Perception, 28(2), 167-181. https://doi.org/10.1068/p2737

1128 Mon-Williams, M., Tresilian, J. R., Plooy, A., Wann, J. P., \& Broerse, J. (1997). Looking at the task in hand: Vergence eye movements and perceived size. Experimental Brain Research, 117(3), 501-506. https://doi.org/10.1007/s002210050246

1131 Morrison, J. D., \& Whiteside, T. C. (1984). Binocular cues in the perception of distance of a point source of light. Perception, 13(5), 555-566. https://doi.org/10.1068/p130555

1133 Murray, S. O., Boyaci, H., \& Kersten, D. (2006). The representation of perceived angular size in 1134 human primary visual cortex. Nature Neuroscience, 9(3), 429-434.

1135 https://doi.org/10.1038/nn1641

1136 Naber, M., \& Nakayama, K. (2013). Pupil responses to high-level image content. Journal of Vision, 13(6), 7-7. https://doi.org/10.1167/13.6.7

1138 Newman, D. G., \& Ostler, D. (2009, July). Hyperstereopsis Associated with Helmet-Mounted Sighting and Display Systems for Helicopter Pilots [Text]. Aerospace Medical Association.

1141 Ono, H., \& Comerford, J. (1977). Stereoscopic depth constancy. In W. Epstein (Ed.), Stability and constancy in visual perception: Mechanisms and process. Wiley. 
1143 Ono, H., Mitson, L., \& Seabrook, K. (1971). Change in convergence and retinal disparities as an explanation for the wallpaper phenomenon. Journal of Experimental Psychology, 91, 1-10. https://doi.org/10.1037/h0031795

1146 Pouget, A., \& Sejnowski, T. J. (1994). A neural model of the cortical representation of egocentric

1147 distance. Cerebral Cortex (New York, N.Y.: 1991), 4(3), 314-329.

$1148 \quad$ https://doi.org/10.1093/cercor/4.3.314

1149 Predebon, J. (1992). The role of instructions and familiar size in absolute judgments of size and

1150 distance. Perception \& Psychophysics, 51(4), 344-354. https://doi.org/10.3758/BF03211628

1151 Priestley, J. (1772). The History and Present State of Discoveries Relating to Vision, Light, and Colours. J.

1152 Johnson.

1153 Prins, N., \& Kingdom, F. A. A. (2018). Applying the Model-Comparison Approach to Test

1154 Specific Research Hypotheses in Psychophysical Research Using the Palamedes Toolbox.

1155 Frontiers in Psychology, 9. https://doi.org/10.3389/fpsyg.2018.01250

1156 Prins, N., \& Kingdom, F. A. A. (2019).

1157 http://www.palamedestoolbox.org/hierarchicalbayesian.html

1158 Priot, A. E., Neveu, P., Philippe, M., \& Roumes, C. (2012). Adaptation to alterations of apparent

1159 distance in stereoscopic displays: From lab to hyperstereopsis. 2012 International Conference

1160 on 3D Imaging (IC3D), 1-7. https://doi.org/10.1109/IC3D.2012.6615123

1161 Priot, A.-E., Laboissière, R., Plantier, J., Prablanc, C., \& Roumes, C. (2011). Partitioning the

1162 components of visuomotor adaptation to prism-altered distance. Neuropsychologia, 49(3),

1163 498-506. https://doi.org/10.1016/j.neuropsychologia.2010.11.028

1164 Priot, A.-E., Laboissière, R., Sillan, O., Roumes, C., \& Prablanc, C. (2010). Adaptation of

1165 egocentric distance perception under telestereoscopic viewing within reaching space.

1166 Experimental Brain Research, 202(4), 825-836. https://doi.org/10.1007/s00221-010-2188-4 
1167 Priot, A.-E., Vacher, A., Vienne, C., Neveu, P., \& Roumes, C. (2018). The initial effects of

1168 hyperstereopsis on visual perception in helicopter pilots flying with see-through helmet-

1169 mounted displays. Displays, 51, 1-8. https://doi.org/10.1016/j.displa.2017.11.002

1170 Pylyshyn, Z. (1999). Is vision continuous with cognition?: The case for cognitive impenetrability

1171 of visual perception. Behavioral and Brain Sciences, 22(3), 341-365.

1172 https://doi.org/10.1017/S0140525X99002022

1173 Quinlan, D. J., \& Culham, J. C. (2007). FMRI reveals a preference for near viewing in the human

1174 parieto-occipital cortex. NeuroImage, 36(1), 167-187.

1175 https://doi.org/10.1016/j.neuroimage.2007.02.029

1176 Ramsay, A. I. G., Carey, D. P., \& Jackson, S. R. (2007). Visual-proprioceptive mismatch and the

1177 Taylor illusion. Experimental Brain Research, 176(1), 173-181.

1178 https://doi.org/10.1007/s00221-006-0609-1

1179 Regan, D., Erkelens, C. J., \& Collewijn, H. (1986). Necessary conditions for the perception of

1180 motion in depth. Investigative Ophthalmology \& Visual Science, 27(4), 584-597.

1181 Richards, W. (1968). Spatial remapping in the primate visual system. Kybernetik, 4(4), 146-156.

1182 https://doi.org/10.1007/BF00288548

1183 Rogers, B. (2009). Are stereoscopic cues ignored in telestereoscopic viewing? Journal of Vision,

1184 9(8), 288-288. https://doi.org/10.1167/9.8.288

1185 Rogers, B. (2017). Perception: A Very Short Introduction. Oxford University Press.

1186 Rogers, B. J. (2011). Information, illusion, and constancy in telestereoscopic viewing. In L. R.

1187 Harris \& M. R. M. Jenkin, Vision in 3D Environments. Cambridge University Press.

1188 Rogers, B. J., \& Bradshaw, M. F. (1995). Disparity Scaling and the Perception of Frontoparallel

1189 Surfaces. Perception, 24(2), 155-179. https://doi.org/10.1068/p240155

1190 Rouder, J. N., Speckman, P. L., Sun, D., Morey, R. D., \& Iverson, G. (2009). Bayesian t tests for 1191 accepting and rejecting the null hypothesis. Psychonomic Bulletin \& Review, 16(2), 225-237.

1192 https://doi.org/10.3758/PBR.16.2.225 
1193 Saleem, A. B., Diamanti, E. M., Fournier, J., Harris, K. D., \& Carandini, M. (2018). Coherent encoding of subjective spatial position in visual cortex and hippocampus. Nature, 562(7725), 124-127. https://doi.org/10.1038/s41586-018-0516-1

Siegel, H., \& Duncan, C. P. (1960). Retinal Disparity and Diplopia vs. Luminance and Size of Target. The American Journal of Psychology, 73(2), 280-284. https://doi.org/10.2307/1419906

Šikl, R., Šimecček, M., Porubanová-Norquist, M., Bezdíček, O., Kremláček, J., Stodůlka, P., Fine, I., \& Ostrovsky, Y. (2013). Vision after 53 years of blindness. I-Perception, 4(8), 498-507.

Slater, A., Mattock, A., \& Brown, E. (1990). Size constancy at birth: Newborn infants' responses to retinal and real size. Journal of Experimental Child Psychology, 49(2), 314-322. https://doi.org/10.1016/0022-0965(90)90061-C

Smith, R. (1738). A Compleat System of Opticks in Four Books, Viæ. A Popular, a Mathematical, a Mechanical, and a Philosophical Treatise. To which are Added Remarks Upon the Whole. By Robert Smith. author, and sold there.

Sobel E.C., \& Collett T.S. (1991). Does vertical disparity scale the perception of stereoscopic

Sperandio, I., \& Chouinard, P. A. (2015). The Mechanisms of Size Constancy. Multisensory Research, 28(3-4), 253-283. https://doi.org/10.1163/22134808-00002483

1213 Sperandio, I., Chouinard, P. A., \& Goodale, M. A. (2012). Retinotopic activity in V1 reflects the perceived and not the retinal size of an afterimage. Nature Neuroscience, 15(4), 540-542.

1216 Sperandio, I., Kaderali, S., Chouinard, P. A., Frey, J., \& Goodale, M. A. (2013). Perceived size change induced by nonvisual signals in darkness: The relative contribution of vergence 
and proprioception. The Journal of Neuroscience: The Official Journal of the Society for

Stuart, G., Jennings, S., Kalich, M., Rash, C., Harding, T., \& Craig, G. (2009). Flight performance using a hyperstereo helmet-mounted display: Adaptation to hyperstereopsis. Proceedings of SPIE - The International Society for Optical Engineering, 7326. https://doi.org/10.1117/12.820500

Suzuki, K. (1986). Effects of oculomotor cues on the apparent size of afterimages. Japanese Psychological Research, 28(4), 168-175. https://doi.org/10.4992/psycholres1954.28.168

Taylor, F. V. (1941). Change in size of the afterimage induced in total darkness. Journal of Experimental Psychology, 29(1), 75-80. https://doi.org/10.1037/h0058125

Tehrani, M. A., Majumder, A., \& Gopi, M. (2016). Correcting perceived perspective distortions using object specific planar transformations. 2016 IEEE International Conference on Computational Photography (ICCP). https://doi.org/10.1109/ICCPHOT.2016.7492868

1231 Trotter, Y., \& Celebrini, S. (1999). Trotter, Y. \& Celebrini, S. Gaze direction controls response gain in primary visual-cortex neurons. Nature 398, 239-242. Nature, 398, 239-242.

1234 Trotter, Y., Celebrini, S., \& Durand, J. B. (2004). Evidence for implication of primate area V1 in neural 3-D spatial localization processing. Journal of Physiology-Paris, 98(1), 125-134.

1237 Trotter, Y., Celebrini, S., Stricanne, B., Thorpe, S., \& Imbert, M. (1992). Modulation of neural stereoscopic processing in primate area V1 by the viewing distance. Science, 257(5074), 1279-1281. https://doi.org/10.1126/science.1519066

1240 Trotter, Y., Celebrini, S., Stricanne, B., Thorpe, S., \& Imbert, M. (1996). Neural processing of 
1243 Trotter, Y., Stricanne, B., Celebrini, S., Thorpe, S., \& Imbert, M. (1993). Neural processing of stereopsis as a function of viewing distance. Oxford University Press. https://0-wwwoxfordscholarshipcom.wam.city.ac.uk/view/10.1093/acprof:oso/9780198547853.001.0001/acprof9780198547853-chapter-027

Urist, M. J. (1959). Afterimages and ocular muscle proprioception. A.M.A. Archives of Ophthalmology, 61(2), 230-232. https://doi.org/10.1001/archopht.1959.00940090232006

Vienne, C., Plantier, J., Neveu, P., \& Priot, A.-E. (2016). The Role of Vertical Disparity in

Viguier, A., Clément, G., \& Trotter, Y. (2001). Distance perception within near visual space. Perception, 30(1), 115-124. https://doi.org/10.1068/p3119 Generale, 10, 231-243.

Von Holst, E. (1955b). 1st der Einfluss der Akkommodation auf die gesehene Dinggrijsse ein "reflektorischer" Vorgang? Naturwissenschaften, 42, 445-446.

1259 Von Holst, E. (1955a). Die Beteiligung von Konvergenz und Akkommodation an der 1260 wahrgenommenen Grossenkonstanz. Naturwissenschaften, 42, 444-445.

1261 Wallach, H., \& Zuckerman, C. (1963). The constancy of stereoscopic depth. The American Journal of Psychology, 76, 404-412.

1263 Watson, A. B. (2017). QUEST+: A general multidimensional Bayesian adaptive psychometric method. Journal of Vision, 17(3), 10-10. https://doi.org/10.1167/17.3.10

1265 Wheatstone, C. (1838). XVIII. Contributions to the physiology of vision. —Part the first. On some remarkable, and hitherto unobserved, phenomena of binocular vision. Philosophical Transactions of the Royal Society of London, 128, 371-394. https://doi.org/10.1098/rstl.1838.0019 
1269 Wheatstone, C. (1852). I. The Bakerian Lecture.-Contributions to the physiology of vision.Part the second. On some remarkable, and hitherto unobserved, phenomena of binocular vision (continued). Philosophical Transactions of the Royal Society of London, 142, 117. https://doi.org/10.1098/rstl.1852.0001

1273 Wildenmann, U., \& Schaeffel, F. (2013). Variations of pupil centration and their effects on video eye tracking. Ophthalmic and Physiological Optics, 33(6), 634-641. https://doi.org/10.1111/opo.12086

1276 Wyatt, H. J. (2010). The human pupil and the use of video-based eyetrackers. Vision Research, 50(19), 1982-1988. https://doi.org/10.1016/j.visres.2010.07.008

1278 Zenkin, G. M., \& Petrov, A. P. (2015). Transformation of the Visual Afterimage Under Subject's Eye and Body Movements and the Visual Field Constancy Mechanisms. Perception, 44(89), 973-985. https://doi.org/10.1177/0301006615594937 